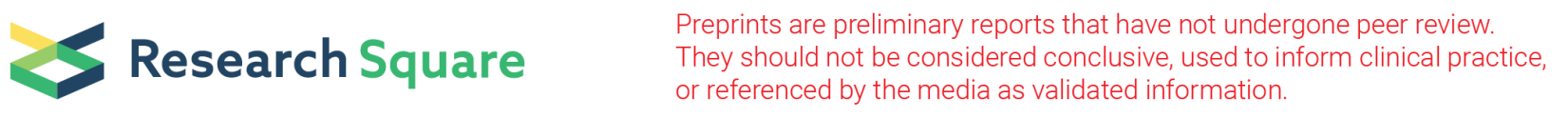

\title{
How do landscape elements affect public health through the physical neighborhood environmental factors? A cross- sectional study of a subtropical high-density city, Guangzhou
}

\author{
Yongli Fang \\ South China Agricultural University https://orcid.org/0000-0001-9803-5671 \\ Qingmin Que \\ South China Agricultural University \\ Ruoxiang Tu \\ South China Agricultural University \\ Yijun Liu \\ South China Agricultural University \\ Wei Gao ( gaowei@scau.edu.cn ) \\ South China Agricultural University https://orcid.org/0000-0002-0951-2438
}

\section{Research}

Keywords: Landscape architecture, Environmental factors; General health, Urban regeneration, Mediation analysis, Correlation analysis, Cross-sectional study, Greenness, Blue space

Posted Date: April 30th, 2021

DOI: https://doi.org/10.21203/rs.3.rs-432184/v1

License: (ㄷ) (i) This work is licensed under a Creative Commons Attribution 4.0 International License. Read Full License 


\section{Abstract}

BACKGROUND: Neighborhood landscapes and environments influence public health through multiple pathways, but few studies have assessed their effects in high-density cities in subtropical monsoon regions, especially mediating pathways of the physical environmental factors.

Purpose: Objectives of this study are to explore associations between neighborhood landscape elements and public health in a subtropical high-density urban context, elucidate mediating effects of physical environmental factors, and propose corresponding neighborhood renewal strategies.

METHODS: Nine sampling sites were selected in Guangzhou, China, and cross-sectional health data were collected from 438 participating residents using the SF-36 scale. Landscape elements of the neighborhoods, including greenness, blue spaces, walking trail systems, hard open spaces, landscape architecture, and dedicated sports spaces were mapped by unmanned aerial vehicle surveys. Six physical environmental factors were also measured in the surveys: the heat stress index (HSI), relative humidity (RH), average wind speed (AWS), negative oxygen ions (NOI), $<2.5 \mu \mathrm{M}$ particulate matter $\left(\mathrm{PM}_{2.5}\right)$, illumination (I), and noise $(\mathrm{N})$. Analysis of variance (ANOVA) and general linear models were used to explore differences between neighborhoods in landscape elements. Relationships between public health and both landscape elements and physical environmental factors, as well as the mediating pathways involved, were explored by correlation analysis and Mediation analyses.

Results: I, $\mathrm{RH}, \mathrm{HSI}, \mathrm{NOI}$, and $\mathrm{PM}_{2.5}$ were significantly correlated with public health in the neighborhoods, as were greenness, blue spaces, walking trail systems, and hard open spaces. No significant correlations were found between public health and either landscape architecture or dedicated sports spaces. Multiple mediation analysis showed that greenness, blue spaces and hard open spaces significantly affected public health, with mediation by I, HSI and NOI, while walking trail systems had significant effects on public health mediated by I, HSI and NOI, but the total mediation effect was not significant.

Conclusion: In subtropical high-density neighborhood, landscape elements have close associations with public health, especially greenness, blue spaces, walking trail systems, and hard open spaces, mainly mediated by effects on light, thermal, and atmospheric environments. Low-quality landscape architecture and space areas do not promote public health. These closely related landscape elements and physical environments need careful attention in community renewal efforts.

\section{Introduction}

The origins of modern urban living environment planning and design are closely related to public health. Early examples include requirements of the British Public Health Act 1848 to improve the living environment, Haussmann's renovation of Paris to bring healthy fresh air and sunlight to the city's streets, and the 'Burnham Plan' to beautify Chicago ${ }^{[1]}$. Objectives in all such cases included improvement in people's health. In China, following sharp increases in residential density the neighborhood environment has become a determinant of certain diseases, in addition to general health ${ }^{[2,3]}$. Hence the relationships between environmental factors of neighborhoods and public health have received increasing scholarly attention ${ }^{[4-6]}$

Many empirical studies have shown that the neighborhoods' physical environments are strongly associated with their residents' health ${ }^{[7]}$. Road traffic noise in the neighborhood significantly affects the incidence of cardiovascular disease among adults, and daytime road traffic noise increases their risk of stroke hospitalization ${ }^{[8]}$. The perceived acoustic environment also affects the health status of middle-aged and elderly people ${ }^{[9]}$ and mental health of children ${ }^{[10]}$, while natural sounds (e.g., birds' chirping) are relaxing ${ }^{[11]}$. Regarding the light environment, light intensities can be significantly 
associated with older adults' physical activity levels, physical health and well-being ${ }^{[12]}$, while sunlight can positively affect stress and emotional self-regulation [13]. Light pollution in the neighborhood environment can damage the human eye, skin, and nervous system ${ }^{[14]}$, and acute excess outdoor ultraviolet (UV) exposure can cause adverse reactions such as erythema and edema ${ }^{[15]}$. Both too high and too low temperatures also have adverse effects on the human body [16], thus anticipated global warming is expected to exacerbate health risks ${ }^{[17]}$. The thermal environment can also affect the body's water and salt metabolism, thus further affecting the body's physiological functions and exercise capacity ${ }^{[18]}$. In addition, atmospheric humidity influences human health by affecting transmission of certain viruses ${ }^{[19,20]}$, and may cause some respiratory or allergic diseases, so reducing humidity in the environment can reduce health risks ${ }^{[21] .}$ Moreover, levels of nitrogen dioxide $\left(\mathrm{NO}_{2}\right)$ and polluting particulate matter in the atmospheric environment are strongly associated with respiratory morbidity and mortality $[22,23]$, and fine particulate matter concentrations are positively associated with the incidence of both dementia in the elderly ${ }^{[24]}$ and psychological disorders (e.g., anxiety and depression) in children ${ }^{[25]}$. In contrast, negative oxygen ions in the air can purify the air and alleviate symptomatic responses to other allergens such as dust and mold spores ${ }^{[26]}$, thereby promoting human health. The wind environment generally has indirect synergistic effects with the atmospheric and/or thermal environment on human health as changes in wind direction and speed can change concentrations of air pollutants, etc. ${ }^{[27]}$, and influence local temperatures, thereby mitigating or exacerbating adverse heat island effects ${ }^{[28]}$. Our team has also previously shown that the physical neighborhood environment in a subtropical monsoonal high-density city significantly affects public health [29].

Neighborhoods' landscape elements are also important. Numerous empirical studies have particularly focused on effects of green and blue spaces on public health in communities, mainly exploring their associations with several domains of health (such as physical, mental, and general health), as well as the impact mechanisms ${ }^{[30,31]}$. A recent review concluded that green spaces impact public health by reducing exposure to harmful environmental factors (e.g., air pollution and noise), restoring individual capabilities (e.g., attention and psychophysiological relaxation), and building capacities (e.g., promoting exercise and social cohesion), thereby affecting residents' health and well-being ${ }^{[30]}$. Empirical studies have also shown that green spaces in neighborhoods promote physical activity, social cohesion, and thus adolescents' mental health through their restorative qualities ${ }^{[32]}$. Other studies have found that blue spaces near neighborhoods affect residents' general mental status by promoting physical activity, especially walking [33], and increases in numbers of blue spaces in a neighborhood may have direct positive impacts on mental health, rather than indirect effects through neighborhood social cohesion, as in the case of green spaces ${ }^{[34]}$. In addition, effects of gray spaces in communities or cities, especially pedestrian systems, have often been studied and compared to those of green spaces or elements. Studies show that urban gray routes have less beneficial effects than urban green routes on residents' emotional health due to factors including higher levels of noise, particulate pollutants, and physiological stress ${ }^{[35]}$. In addition to the contrast with green spaces, correlations between walking activity in a neighborhood and both the number and spacing of street intersections in the neighborhood's pedestrian system have been detected ${ }^{[36]}$. Further, an exploration of associations between several landscape elements and the health of older adults in high-density urban Hong Kong showed that landscape elements such as water features, touchable plants, fitness areas, and hard open spaces all had varying perceived importance for older adults ${ }^{[37]}$. Height to width ratios of trails and pavement permeability also affect environmental microclimates and thus human thermal comfort ${ }^{[38]}$. In summary, landscape elements have direct or indirect effects on public health, via multiple multi-dimensional pathways. These mediating pathways are far from fully understood and there are clear needs to elucidate their influence rigorously at fine spatial scales [31], and thus improve understanding of neighborhood landscape elements' effects on public health.

Partly because it is a typical high-density city with a subtropical climate, there have been increasing numbers of studies on neighborhood environments and public health-related factors in Guangzhou (China) recently, mainly focusing on correlations between neighborhood greenness (assessed from satellite images) and residents' health parameters ${ }^{\text {[39-41]. }}$ 
These studies have shown, inter alia, that neighborhood greenness in a high-density city such as Guangzhou can promote residents' health through increases in social cohesion ${ }^{[5]}$ and physical exercise ${ }^{[42]}$, together with strong correlations between the physical environment and residents' health ${ }^{[29]}$. However, it is still not known if (and if so how) other neighborhood landscape elements affect public health through the neighborhood's physical environment.

To help efforts to understand these effects, this study explores pathways mediating effects of various landscape elements and physical environmental factors on public health, in a high-density urban context, using Guangzhou as an example. The landscape elements considered include greenness, blue spaces, walking trail systems, hard open spaces, garden architecture, and specialized sport spaces, which have received much attention in previous studies. The mediating variables considered (to address the extent of direct and indirect effects of landscape elements on residents' health) include the $\mathrm{HSI}, \mathrm{RH}, \mathrm{AWS}, \mathrm{NOI}, \mathrm{PM}_{2.5}$, I and $\mathrm{N}$ (Figure 1). We hypothesized that the landscape elements may influence public health through mediating effects of the physical environmental factors. The findings may extend theoretical foundations for neighborhood-scale landscape architecture initiatives to enhance public health, and recommendations based on them are proposed for such initiatives, particularly in high-density cities of subtropical monsoon regions.

\section{Materials And Methods}

\subsection{Study Site}

Guangzhou $\left(23^{\circ} 6^{\prime} \mathrm{N}, 113^{\circ} 15^{\prime} \mathrm{E}\right)$ is hot and humid year-round, with an average annual temperature of $22.8^{\circ} \mathrm{C}$, and mean temperatures in the hottest and coldest months (July and January) of $30.4^{\circ} \mathrm{C}$ and $15.1^{\circ} \mathrm{C}$, respectively, according to data from the past 30 years ${ }^{[43,44]}$. On average, the daily maximum temperature exceeds $30^{\circ} \mathrm{C}$ for 150 days per year. The cumulative annual average relative humidity in the city is $73 \%$, annual rainfall amounts to about $1910 \mathrm{~mm}$, the longest continuous precipitation is mostly in June, and the cumulative annual average wind speed is $1.5 \mathrm{~m} / \mathrm{s}$, which is typical for a subtropical monsoon climate ${ }^{[43,44]}$. With the rapid economic development and urban expansion in China, Guangzhou has become one of a number of typical high-density cities ${ }^{[45]}$.

Nine sampling sites were selected for the study, located in the Liwan and Yuexiu districts, typical old neighborhoods in the historical city of Guangzhou (Figure 2) with environmental characteristics including high residential density, ageing building stocks and relatively poorly developed infrastructure. However, there are substantial variations in the considered landscape elements among the sites (Table 1).

\subsection{Data Collection}

\subsubsection{Public health information collection}

To assess respondents' self-evaluated health we used a culturally modified form of the 36-item Short Form Survey (SF-36 scale), derived from the Medical Outcomes Study, which has shown good reliability and validity for assessing Guangzhou residents' health ${ }^{[46,47]}$. The SF-36 scale has nine dimensions ${ }^{[48]}$ : four used to measure subjects' physical health

(expressed by a 'Physical Component Summary'), four to measure their mental health (expressed by a 'Mental Component Summary') and a Reported Health Transition (HT) dimension designed to indicate overall changes in health status ${ }^{[49]}$. The four physical health dimensions are Physical Functioning (PF), General Health (GH), Bodily Pain (BP), and Role-Physical (RP), while the mental health dimensions are Vitality (VT), Mental Health (MH), Social Functioning (SF), and Role-Emotional (RE).

A random sampling method was used to recruit participants to assess the physical and mental health status of residents in each of the nine sample sites using the SF-36 scale. 50 questionnaires were distributed to each sample site within one month after the measurement of the environmental factors. Researchers went within each neighborhood and surveyed 
participants face-to-face. All the candidate participants gave informed consent to participate, with reassurance that their participation would be anonymous, and the results would only be used for academic research.. Thus, 450 questionnaires were distributed in the nine sampling sites, and 450 were returned. Twelve with incomplete entries were excluded, and the remaining 438 were included in subsequent analysis. Ages of the respondents ranged from 13 to 88 years (mean 45.1 years, Table 1). Information on scores for each dimension of the SF-36 scale are shown in Table 1.

\subsubsection{Predictors $\square$ Measurement of Landscape Elements}

As already mentioned, the landscape elements considered in this study include greenness, blue spaces, walking trail systems, hard open spaces, sport spaces and garden architecture. All of these have recognized importance in environmental and public health, except garden architecture $[30,31,35-37,41,50]$, which is a major landscape element in the Chinese tradition ${ }^{[51]}$ and was thus also included.

A combination of indicators for the landscape elements were selected that have previously demonstrated effects (direct or indirect) on public health and/or are widely applied Chinese measures of local landscape elements. Greenness was measured in terms of the green space ratio (GSR: green space area/total area), green coverage ratio (GCR: green coverage area/total area), and tree green cover ratio (TGCR: tree coverage area/total green coverage area). GSR and GCR are used for assessing neighborhood greenness in urban construction projects in China ${ }^{[52] ~, ~ a n d ~ T G C R ~ i n d i c a t e s ~ t h e ~ s t r u c t u r e ~ o f ~}$ neighborhood greenness ${ }^{[53]}$ in terms of relative areas of tree and shrub/ground cover.' Note, there is no point using abbreviations if the full terms are also provided at every use. Blue space was measured by the percentage of water area in each neighborhood (PWA: water area/total area), reflecting the amount of water space in the neighborhood. The walking trail system in each neighborhood was measured in terms of trail density (TD: total trail length/total area) and average trail height to width ratio (ATHWR: average of measurements at $50 \mathrm{~m}$ intervals along trails), and average intersection spacing (AIS: average distance between intersections in the neighborhood). TD and AIS reflect the density of walking trail systems ${ }^{[36]}$, and ATHWR reflects the spatial width of the trails ${ }^{[38]}$. Hard open space was measured by the percentage of hard open space (PHOS: area of hard open space/total area), which is distinguished from garden architecture and dedicated sports spaces, and reflects the amount of hard open space in the neighborhood (e.g. small squares). Garden architecture was measured by the percentage of floor area (PGA: garden architecture area/total area). Sports spaces refers to places in the neighborhood dedicated to residents' sports (e.g. courts and fitness spaces), measured by the percentage of floor space (PSS: sports space area/total area), reflecting the amount of dedicated sports space in the neighborhood.

To measure the indicators listed above we used a DJI Mavic 2 pro drone (DJI Innovation Technology Co., Ltd., Shenzhen, China) and Pix4Dcapture mission planning software (Version 4.12.1, Pix4D SA, Prilly, Switzerland) for aerial surveys of the sampling areas, and imported the acquired data into pix4Dmapper (Version 4.5.6, Pix4D SA, Prilly, Switzerland) to generate orthophotos (Figure 3). The orthophotos were then used in conjunction with laser rangefinder data to determine the variables of interest. These were all areal statistics and indices calculated with AutoCAD 2014 (version I.18.0.0, Autodesk, USA) except for the road height to width ratio, which was based on measurements at $50 \mathrm{~m}$ intervals along main roads in each neighborhood. Summary statistics for each neighborhood landscape element are shown in Table 1.

\subsubsection{Mediators $\square$ Measurement of Environmental Factors}

According to China's architectural design standards and relevant studies, the urban physical environment can be divided into six (thermal, humidity, wind, atmospheric, light and acoustic) main components ${ }^{[54]}$. The Heat Stress Index (HSI), Relative Humidity (RH), Average Wind Speed (AWS), illumination (I) and Noisiness (N) were used to characterize the thermal, humidity, wind, light and acoustic environments, respectively, of the sample sites. Negative Oxygen lons (NOI) 
and $<2.5 \mu \mathrm{M}$ particulate matter $\left(\mathrm{PM}_{2.5}\right)$ levels were used to characterize their atmospheric environments in terms of air cleanliness and pollution, respectively. Following previously described procedures ${ }^{[29]}$ we used: a NK3000 handheld weather station (Nielsen-Kellerman , Boothwyn, USA) to measure RH, AWS and HSI; a TES-136 (TES Electrical Electronic Corp., Taipei, China) portable colorimeter to measure l; an TES-1357 noise meter (TES Electrical Electronic Corp., Taipei, China) to measure N; a KEC-900Il oxygen ion detector (Eco Flavone Co., Ltd., Yokohama, Japan) to measure NOI, and KornoGT-1000 laser dust meter (Korno Electronics Co., Ltd., Shenzhen, China ) to measure PM 2.5. These environmental factors were measured at five points in each sampling location, with a centripetal distribution, in October 2020 at 2-hour intervals from 8:00 am to 8:00 pm on two non-consecutive sunny days. Results of the environmental factor measurements are shown in Table 1.

Table 1 Sample and variable description statistics table

\begin{tabular}{|c|c|}
\hline Characteristics and Variables & Sample description \\
\hline Sociodemographics & Total $\square N=438 \square$ \\
\hline Male $\llbracket n \llbracket \% \square$ & $232 \square 52.97 \% \square$ \\
\hline Age $\llbracket$ mean $\square S D \square$ & $45.08 \square 18.55 \square$ \\
\hline \multicolumn{2}{|l|}{ Education $\square \mathrm{n} \square \% \square$} \\
\hline Primary school or below & 87ロ19.86ロ \\
\hline Secondary school & $221 \square 50.46 \square$ \\
\hline College or above & $130 \square 29.68 \square$ \\
\hline \multicolumn{2}{|l|}{ Public Health Information } \\
\hline \multicolumn{2}{|l|}{ SF-36₫mean $\square S D \square$} \\
\hline SFTOTAL & 124.513凸15.092₫ \\
\hline $\mathrm{BP}$ & $84.941 \square 16.044 \square$ \\
\hline $\mathrm{PF}$ & $87.009 \square 17.471 \square$ \\
\hline $\mathrm{RP}$ & $74.715 \square 34.182 \square$ \\
\hline $\mathrm{GH}$ & $70.210 \square 21.175 \square$ \\
\hline VT & 73.710ロ15.607ロ \\
\hline SF & 95.177ロ19.920ロ \\
\hline $\mathrm{RE}$ & $76.865 \square 33.334 \square$ \\
\hline $\mathrm{MH}$ & $75.744 \square 15.835 \square$ \\
\hline HT & $49.715 \square 20.469 \square$ \\
\hline \multicolumn{2}{|l|}{ Predictors $\square$ Landscape Elements } \\
\hline Green space ratio, $\mathrm{m}^{2} / \mathrm{m}^{2} \llbracket$ mean $\llbracket \mathrm{SD} \square$ & $0.026 \square 0.026 \square$ \\
\hline Green coverage ratio, $\mathrm{m}^{2} / \mathrm{m}^{2} \llbracket$ mean $\square \mathrm{SD} \square$ & $0.132 \square 0.057 \square$ \\
\hline Tree green cover ratio, $\mathrm{m}^{2} / \mathrm{m}^{2} \square$ mean $\square \mathrm{SD} \square$ & $0.834 \square 0.034 \square$ \\
\hline Percentage of water area, $\mathrm{m}^{2} / \mathrm{m}^{2} \llbracket$ mean $\square$ SD $\square$ & $0.014 \square 0.021 \square$ \\
\hline Trail density, $\mathrm{m} / \mathrm{m} \llbracket \llbracket$ mean $\square \mathrm{SD} \square$ & $0.04800 .014 \square$ \\
\hline Average trail height to width ratio, $\mathrm{m} / \mathrm{m} \rrbracket$ mean $\square \mathrm{SD} \square$ & $3.178 \square 1.053$ \\
\hline Average intersection spacing, $\mathrm{m} \rrbracket$ mean $\square \mathrm{SD} \square$ & $\begin{array}{l}05.460 \square 21.899 \square \\
0.030 \square 0.020 \square\end{array}$ \\
\hline Percentage of hard open space, $\mathrm{m}^{2} / \mathrm{m}^{2} \llbracket$ mean $\llbracket \mathrm{SD} \square$ & $0.002 \square 0.0020$ \\
\hline Percentage of garden architecture area, $\mathrm{m}^{2} / \mathrm{m}^{2} \llbracket$ mean $\square \mathrm{SD} \square$ & $0.003 \square 0.003 \square$ \\
\hline \multicolumn{2}{|l|}{ Percentage of sports space area, $\mathrm{m}^{2} / \mathrm{m}^{2} \llbracket$ mean $\square \mathrm{SD} \square$} \\
\hline \multicolumn{2}{|l|}{ Mediators $\square$ Physical Environment Factor } \\
\hline $\mathrm{N}, \mathrm{db} \square$ mean $\square \mathrm{SD} \square$ & $55.64 \square 3.19 \square$ \\
\hline $\mathrm{I}, \mathrm{lm} \rrbracket \mathrm{mean} \square \mathrm{SD} \square$ & 8285.87ロ9862.25ロ \\
\hline AWS, m/s $\llbracket$ mean $\llbracket \mathrm{SD} \square$ & $0.79 \square 0.39 \square$ \\
\hline $\mathrm{RH}, \% \square \mathrm{mean} \square \mathrm{SD} \square$ & $55.9 \square 6.25 \square$ \\
\hline HSI $\square m e a n \llbracket S D \square$ & $28.33 \square 2.48 \square$ \\
\hline $\mathrm{NOI} \square \mathrm{mean} \square \mathrm{SD} \square$ & $0.66 \square 0.23 \square$ \\
\hline $\mathrm{PM} 2.5 \square \mu \mathrm{g} / \mathrm{m} \llbracket$ mean $₫ \mathrm{SD} \square$ & $38.64 \square 9.50 \square$ \\
\hline
\end{tabular}

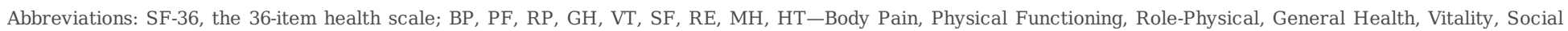

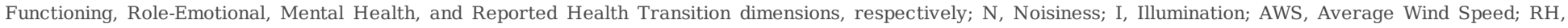
Relative Humidity; HSI, Heat Stress Index; NOI, Negative Oxygen Ions; PM2.5, Fine Particulate Matter.

\subsection{Statistical Analysis}

Before analyzing the results, we tested the reliability of the SF-36 scale in the focal context by applying split-half (Spearman-Brown) reliability and Cronbach's a internal consistency tests, with acceptability thresholds for the obtained coefficients of $>0.7$ and $>0.6$, respectively ${ }^{[55,56]}$. We also tested its content, construct validity by calculating Pearson correlation coefficients between dimensions and between the dimensions, and total scores, respectively. In addition, we extracted common factors (by Principal Component Analysis, PCA) with characteristic roots greater than 1 for the eight 
dimensions, calculated loadings of these factors for each dimension by the maximum variance rotation method, and evaluated their structural validity by matching them with theoretical models ${ }^{[46]}$.

General linear models were applied to detect significant differences between communities and potential associations between environmental differences and health disparities. In the ANOVA, the total (SFTOTAL) scores obtained from the SF-36 survey was the dependent variable, neighborhood a fixed variable, age and education covariates, and gender a random variable.

To further clarify relationships between the landscape elements, physical environmental factors and public health, correlations between their indicators were examined, then indicators of landscape elements and physical environmental factors that were not significantly correlated with public health were discarded..

IBM SPSS 24.0 (version 24.0, IBM, Armonk, NY , USA) was used for all the above analyses.

Numerous scholars have used a mediation effect model ${ }^{[57]}$, as illustrated in Figure 4, to explore the mechanisms of landscape elements' and environmental factors' health effects ${ }^{[32,58,59]}$. Such tests have been divided into three categories: the causal steps approach (testing the regression coefficients once), the difference in coefficients approach (testing the significance of $c-c^{\prime}$ ), and the products of coefficients approach (testing the significance of ab), where $a, b, c$, and $c^{\prime}$ have meanings shown in Figure $4{ }^{[60,61]}$. Non-normally distributed mediating variables can be handled in the product of coefficients method, leading to asymmetric confidence intervals for models of multiple mediating effects, using data obtained from small or medium-sized samples such as those in this study by bias-corrected percentile bootstrapping ${ }^{[62]}$. Therefore, we applied a multiple mediation model of this type (Figure 5) ${ }^{[63]}$, using the mentioned landscape elements as independent variables, mentioned physical environment factors as mediating variables, and public health parameters as dependent variables. The relevant indicators were standardized and processed using percentile bootstrap bias correction with Model 4 in SPSS macro PROCESS v.2.16 ${ }^{[64]}$. A set of 5,000 Bootstrap samples was drawn to estimate $95 \%$ confidence intervals for mediation effects, which were regarded as significant if they did not contain 0

${ }^{[65]}$. Mediating effect ratios were calculated using the following equation ${ }^{[62,66]}$, regarding negative values of $a_{i}$ or $b_{i}$ as indicative of masking effects, and calculating strengths of mediating effects using absolute values ${ }^{[57]}$ :

Mediating effect ratio: $M E R_{i}=\frac{\left|a_{i} b_{i}\right|}{c^{\prime}+\sum_{i=1}^{n}\left|a_{i} b_{i}\right|}$

\section{Results}

3.1 Reliability and validity of the SF-36 scale

\subsubsection{Reliability of the scale}

We obtained Spearman-Brown correction and overall Cronbach's a coefficients of 0.834 and 0.840 , respectively for the scale, comfortably more than the thresholds for acceptable reliability of 0.7 and 0.6 , respectively, strongly indicating that it has sufficient internal consistency and reliable ability to detect between-area differences in health parameters.

\subsubsection{Validity of the SF-36 Health Scale}

Content validity: The correlations between scores for each dimension of the SF-36 Health Scale and total scores, and correlations between the dimensions, were highly significant ( $<<0.001$; Table 2$)$, strongly indicating that it has sufficient content validity 
Table 2 Correlation coefficients between subscales and between subscales and total scores.

\begin{tabular}{|c|c|c|c|c|c|c|c|c|c|}
\hline & $\mathrm{BP}$ & $\mathrm{PF}$ & $\mathrm{RP}$ & $\mathrm{GH}$ & VT & $\mathrm{SF}$ & $\mathrm{RE}$ & $\mathrm{MH}$ & HT \\
\hline $\mathrm{PF}$ & $.570^{* *}$ & & & & & & & & \\
\hline $\mathrm{RP}$ & $.544^{* *}$ & $.490^{* *}$ & & & & & & & \\
\hline $\mathrm{GH}$ & $.525^{* *}$ & $.496^{* *}$ & $.472^{* *}$ & & & & & & \\
\hline VT & $.415^{* *}$ & $.484^{* *}$ & $.474^{* *}$ & $.492^{* *}$ & & & & & \\
\hline $\mathrm{SF}$ & $.559^{* *}$ & $.608^{* *}$ & $.522^{* *}$ & $.583^{* *}$ & $.573^{* *}$ & & & & \\
\hline $\mathrm{RE}$ & $.309^{* *}$ & $.222^{* *}$ & $.545^{* *}$ & $.321^{* *}$ & $.371^{* *}$ & $.468^{* *}$ & & & \\
\hline $\mathrm{MH}$ & $.233^{* *}$ & $.195^{* *}$ & $.275^{* *}$ & $.336^{* *}$ & $.594^{* *}$ & $.427^{* *}$ & $.387^{* *}$ & & \\
\hline HT & $.351^{* *}$ & $.300^{* *}$ & $.327^{* *}$ & $.403^{* *}$ & $.208^{* *}$ & $.293^{* *}$ & $.222^{* *}$ & $.130^{* *}$ & \\
\hline SFTOTAL & $.680^{* *}$ & $.722^{* *}$ & $.674^{* *}$ & $.788^{* *}$ & $.796^{* *}$ & $.794^{* *}$ & $.529^{* *}$ & $.652^{* *}$ & $.426^{* *}$ \\
\hline
\end{tabular}

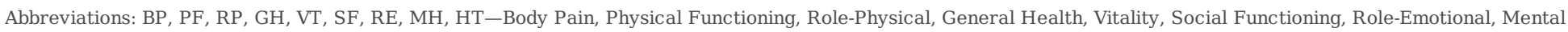
Health, and Reported Health Transition dimensions, respectively; **, $\mathrm{P}<0.01$ (indicating highly significant correlation).

Construct validity[PCA was performed for each dimension of the scale except $\mathrm{HT}$, and two common factors with root $>1$ were extracted, which jointly explained $65.2 \%$ of the variance. Rotation using the Kaiser normalized maximum variance method to obtain loadings of each dimension on the two communal factors (Table 3 ) indicated that the PF, BP, GH, RP, and SF dimensions were correlated with the communal factor $\mathrm{F} 1$, and the $\mathrm{MH}, \mathrm{RE}$, and $\mathrm{VT}$ dimensions were correlated with the communal factor $\mathrm{F} 2$. The actual PF, BP, GH, MH, and VT models are completely consistent with the respective theoretical models, the actual RE and SF models are partially consistent with the respective theoretical models, and the actual RP model is not consistent with the theoretical model, but its loadings on the metric factors F1 and F2 are close to those of the corresponding theoretical model. In summary, the measurements are highly consistent with the overall conceptual model.

Table 3 Actual and theoretical factor loadings for models of dimensions of the SF-36 scale

\begin{tabular}{lcccc}
\hline Dimensions & \multicolumn{2}{c}{ Actual model } & \multicolumn{2}{c}{ Theoretical model } \\
\cline { 2 - 5 } & F1 & F2 & Physiological factors & Psychological factors \\
\hline PF & 0.841 & 0.084 & $\geq 0.70$ & $\mathrm{r} \leq 0.30$ \\
BP & 0.820 & 0.131 & $\geq 0.70$ & $\mathrm{r} \leq 0.30$ \\
\hline $\mathrm{GH}$ & 0.694 & 0.468 & $0.30 \square \mathrm{r} \square 0.70$ & $0.30 \square \mathrm{r} \square 0.70$ \\
\hline RP & 0.657 & 0.385 & $\geq 0.70$ & $\mathrm{r} \leq 0.30$ \\
MH & 0.052 & 0.881 & $\mathrm{r} \leq 0.30$ & $\geq 0.70$ \\
RE & 0.256 & 0.673 & $\mathrm{r} \leq 0.30$ & $\geq 0.70$ \\
\hline VT & 0.442 & 0.685 & $0.30 \square \mathrm{r} \square 0.70$ & $0.30 \square \mathrm{r} \square 0.70$ \\
\hline SF & 0.694 & 0.648 & $0.30 \square \mathrm{r} \square 0.70$ & $\geq 0.70$ \\
\hline
\end{tabular}

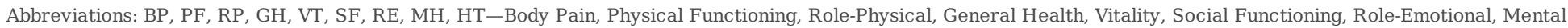

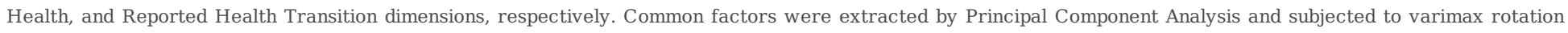
with Kaiser normalization.

\subsection{Analysis of variance}

Results of the ANOVA using the general linear model are shown in Table 4. The ANOVA revealed a highly significant association between residents' age and health (total SF-36 score), and significant associations between their health and both education level and neighborhood. Thus, although other factors are important, it clearly indicated that the mechanisms whereby neighborhood landscape and environmental factors influence public health warrant further attention. 
Table 4 General linear model of indicated factors' effects on resident's heath (SFTOTAL scores).

\begin{tabular}{|c|c|c|c|c|c|c|}
\hline & & Sum Squares & Degree of Freedom & Mean Square & F Value & $\mathrm{p}$ Value \\
\hline \multirow[t]{2}{*}{ Intercept Distance } & Assumptions & 133905.20 & 1 & 133905.20 & 767.41 & 0.000 \\
\hline & Error & 71698.22 & 410.903 & $174.49^{\mathrm{a}}$ & & \\
\hline \multirow[t]{2}{*}{ Age } & Assumptions & 4089.53 & 1 & 4089.53 & 23.21 & 0.000 \\
\hline & Error & 73656.60 & 418 & $176.21^{\mathrm{b}}$ & & \\
\hline \multirow[t]{2}{*}{ Education } & Assumptions & 891.57 & 1 & 891.57 & 5.06 & 0.025 \\
\hline & Error & 73656.60 & 418 & $176.21^{\mathrm{b}}$ & & \\
\hline \multirow[t]{2}{*}{ Neighborhood } & Assumptions & 6898.19 & 8 & 862.27 & 3.47 & 0.049 \\
\hline & Error & 1999.26 & 8.039 & $248.70^{c}$ & & \\
\hline \multirow[t]{2}{*}{ Gender } & Assumptions & 85.18 & 1 & 85.18 & 0.34 & 0.574 \\
\hline & Error & 1998.53 & 8.035 & $248.72^{d}$ & & \\
\hline \multirow[t]{2}{*}{ Neighborhood * Gender } & Assumptions & 1991.59 & 8 & 248.95 & 1.41 & 0.189 \\
\hline & Error & 73656.60 & 418 & $176.21 \mathrm{~b}$ & & \\
\hline
\end{tabular}

Abbreviations: a, .019 MS(Gender) + .981 MS(Error); b, MS(Error); c, .997 MS (Neighborhood * Gender) + .003 MS(Error); d, .997 MS(Neighborhood* Gender) + .003 MS(Error)

\subsection{Correlation analysis}

Overall physical health (HI1) and mental health (HI2) scores for the participants were calculated using data shown in Table 3, then correlations between total health (SFTOTAL), HI1 and HI2 scores with environmental factors and landscape elements were analyzed (Tables 5 and 6, respectively). Correlations between environmental factors and landscape elements were also analyzed (Table 7).

Results of the correlation analysis show (Table 5) that five landscape elements (GSR, GCR, PWA, TD, and ATHWR) were highly significantly correlated, and two (PHOS and AIS) were significantly correlated with total health scores. In addition, five (GSA, GCR, PWA, TD, ATHWR, and PHOS) were highly significantly correlated with physiological health scores, while GCR and ATHWR were highly significantly correlated (and both GSR and PWA significantly correlated) with psychological health scores. TGCR, PGA and PSS were not significantly correlated with total, physiological or psychological health scores, indicating that these three indicators were not significantly correlated with public health. Thus, to simplify the mediating pathways they were excluded from subsequent analysis.

The correlations between landscape elements and SFTOTAL decreased in the following order: ATHWR $>$ GCR $>$ GSR $>$ TD > PHOS > PWA > PSS > PGA > TGCR. Their correlations with physiological health scores decreased in the order GCR > GSR> TD $>$ ATHWR $>$ PHOS $>$ PWA $>$ AIS $>$ TGCR $>$ PSS $>$ PGA, and their correlations with psychological health scores decreased in the order ATHWR > GCR > GSR > PWA $>$ PHOS $>$ AIS > TD > PSS > TGCR > PGA.

Table 5 Results of Pearson correlation analysis of landscape elements with total health, physical health, and mental health scores

\begin{tabular}{lcccccccccc}
\hline Health Subscales & GSR & GCR & TGCR & PWA & TD & ATHWR & AIS & PHOS & PGA & PSS \\
\hline SFTOTAL & $.227^{* *}$ & $.251^{* *}$ & 0.006 & $.168^{* *}$ & $-.171^{* *}$ & $-.252^{* *}$ & $.123^{*}$ & $.169^{* *}$ & -0.008 & -0.015 \\
HI1 & $.180^{* *}$ & $.194^{* *}$ & -0.060 & $.125^{* *}$ & $-.170^{* *}$ & $-.156^{* *}$ & 0.066 & $.130^{* *}$ & 0.023 & 0.027 \\
HI2 & $.112^{*}$ & $.136^{* *}$ & 0.028 & $.110^{*}$ & -0.041 & $-.165^{* *}$ & 0.061 & 0.085 & -0.016 & -0.035 \\
\hline
\end{tabular}

Abbreviations: HI1, Physical Component Summary score; HI2, Mental Component Summary score; GSR, green space ratio; GCR, green coverage ratio; TGCR, tree green cover ratio; PWA, percentage of water area; TD, trail density; ATHWR, average trail height to width ratio; AIS, average intersection spacing; PHOS, percentage of hard open space; PGA, percentage of garden architecture area; PSS, percentage of sports space area; * significant $(\mathrm{P}<0.05)$; $* *$ highly significant $(\mathrm{p}<0.01)$.

SFTOTAL scores were also highly significantly correlated with two environmental factors (I and $\mathrm{RH})$ and significantly correlated with NOI, HSI and PM2.5 (Table 6). Two environmental factors (I and NOI) were highly significantly correlated, and another two $\left(\mathrm{RH}\right.$ and $\left.\mathrm{PM}_{2.5}\right)$ significantly correlated with physiological health scores. In addition NOI was highly 
significantly correlated with psychological health scores. N and AWS were not significantly correlated with total, physiological or psychological health scores, and thus were excluded from subsequent analysis.

The correlations between environmental factors and SFTOTAL declined in the order NOI $>$ I $>$ RH $>$ HSI $>$ PM2.5 $>$ N $>$ AWS. The correlations between environmental factors and physiological health scores declined in the order $1>\mathrm{NOI}>\mathrm{PM} 2.5>\mathrm{RH}$ $>\mathrm{HSI}>\mathrm{N}>\mathrm{AWS}$. The correlations between environmental factors and psychological health scores declined in the order $\mathrm{NOI}>\mathrm{RH}>\mathrm{AWS}>\mathrm{I}>\mathrm{HSI}>\mathrm{PM} 2.5>\mathrm{N}$.

Table 6 Results of Pearson correlation analysis of relationships between total health (SFTOTAL), physical health and mental health scores and environmental factors

\begin{tabular}{lccccccc}
\hline Health Subscales & $\mathrm{N}$ & $\mathrm{I}$ & AWS & $\mathrm{RH}$ & HSI & NOI & PM2.5 \\
\hline SFTOTAL & 0.061 & $-.172^{* *}$ & 0.021 & $.132^{* *}$ & $-.116^{*}$ & $.228^{* *}$ & $.104^{*}$ \\
HI1 & 0.062 & $-.165^{* *}$ & -0.023 & $.101^{*}$ & -0.088 & $.157^{* *}$ & $.104^{*}$ \\
HI2 & 0.004 & -0.043 & 0.061 & 0.064 & -0.040 & $.139^{* *}$ & 0.020 \\
\hline
\end{tabular}

Abbreviations: HI1, Physical Component Summary score; HI2, Mental Component Summary score. N, Noisiness; I, Illumination; AWS, Average Wind Speed; RH, Relative Humidity; HSi, Heat Stress Index; NOI, Negative Oxygen Ions: $\mathrm{PM}_{2.5}$, Fine Particulate Matter; * significant ( $\left.\mathrm{P}<0.05\right)$; ** highly significant (p<0.01).

The analysis of correlations between landscape elements and environmental factors (Table 7) showed that TGCR was not significantly correlated with $\mathrm{N}$ and I, ATHWR was not significantly correlated with N, PHOS was not significantly correlated with AWS and RH, PGA was not significantly correlated with $\mathrm{N}, \mathrm{RH}, \mathrm{HSI}$, or $\mathrm{NOI}$, and PSS was not significantly correlated with $\mathrm{N}$. The remaining landscape elements showed significant correlations with environmental factors, indicating that landscape elements are closely related in neighborhoods of high-density cities, and further mediation analysis is needed to clarify the pathways affecting public health.

Table 7 Results of Pearson correlation analysis between environmental factors and landscape elements

\begin{tabular}{ccccccccccc}
\hline & GSR & GCR & TGCR & PWA & TD & ATHWR & AIS & PHOS & PGA & PSS \\
\hline N & $.097^{*}$ & $.101^{*}$ & 0.025 & $-.353^{* *}$ & $-.418^{* *}$ & 0.019 & $.374^{* *}$ & $.240^{* *}$ & 0.005 & 0.067 \\
I & $-.383^{* *}$ & $-.387^{* *}$ & 0.045 & $-.283^{* *}$ & $.904^{* *}$ & $.543^{* *}$ & $-.477^{* *}$ & $-.133^{* *}$ & $.344^{* *}$ & $-.112^{*}$ \\
\hline AWS & $.275^{* *}$ & $.225^{* *}$ & $.114^{*}$ & $.616^{* *}$ & $.551^{* *}$ & $-.231^{* *}$ & $-.224^{* *}$ & 0.011 & $.343^{* *}$ & $-.662^{* *}$ \\
\hline RH & $.274^{* *}$ & $.415^{* *}$ & $.280^{* *}$ & $.630^{* *}$ & $-.599^{* *}$ & $-.524^{* *}$ & $.116^{*}$ & 0.084 & 0.068 & $.121^{*}$ \\
\hline HSI & $-.631^{* *}$ & $-.447^{* *}$ & $-.284^{* *}$ & $-.322^{* *}$ & $.191^{* *}$ & $.536^{* *}$ & $-.378^{* *}$ & $-.288^{* *}$ & 0.087 & $.505^{* *}$ \\
NOI & $.855^{* *}$ & $.844^{* *}$ & $.232^{* *}$ & $.507^{* *}$ & $-.253^{* *}$ & $-.810^{* *}$ & $.450^{* *}$ & $.670^{* *}$ & 0.004 & $-.226^{* *}$ \\
\hline PM2.5 & $.180^{* *}$ & $.314^{* *}$ & $.117^{*}$ & $.190^{* *}$ & $-.836^{* *}$ & $-.341^{* *}$ & $.490^{* *}$ & $.210^{* *}$ & $-.300^{* *}$ & $.571^{* *}$ \\
\hline
\end{tabular}

Abbreviations: GSR, green space ratio; GCR, green coverage ratio; TGCR, tree green cover ratio; PWA, percentage of water area; TD, trail density; ATHWR, average trail height to width ratio; AIS, average intersection spacing; PHOS, percentage of hard open space; PGA, percentage of garden architecture area; PSS, percentage of sports space area; N, Noisiness; I, Illumination; AWS, Average Wind Speed; RH, Relative Humidity; HIS, Heat Stress Index; NOI, Negative Oxygen Ions: $\mathrm{PM}_{2.5}$, Fine Particulate Matter. *, p<0.05; **, p<0.01.

Table 8 Multiple mediation models linking adjusted landscape elements to public health (Outcome: SFTOTAL)

\begin{tabular}{|c|c|c|c|c|c|c|c|c|}
\hline \multirow[t]{2}{*}{ Landscape } & \multirow[t]{2}{*}{ Total Effect } & \multirow{2}{*}{$\begin{array}{l}\text { Total } \\
\text { Indirect } \\
\text { Effect }\end{array}$} & \multirow[t]{2}{*}{ Direct effect } & \multicolumn{5}{|c|}{ Specific indirect effects (mediators tested one-at-a-time) } \\
\hline & & & & I & RH & HSI & NOI & PM2.5 \\
\hline GSR & $0.22 \square 0.15 \square 0.29 \square^{*}$ & $0.18 \square 0.0100 .35 \square^{*}$ & $0.04 \square-0.14 \llbracket 0.23 \square$ & $0.07 \square 0.01 \square 0.14 \square^{*}$ & $0.01 \square-0.02 \square 0.04 \square$ & $-0.13 \square-0.23 \square-0.03 \square^{*}$ & $0.25 \square 0.07 \square 0.42 \square^{*}$ & $-0.02 \square-0.05 \square 0.01 \square$ \\
\hline GCR & $0.25 \square 0.16 \square 0.32 \square^{*}$ & $0.2 \square-0.01 \square 0.40 \square$ & $0.05 \square-0.17 \llbracket 0.26 \square$ & $0.07 \square 0.01 \square 0.14 \square^{*}$ & $0.01 \square-0.04 \square 0.05 \square$ & $-0.09 \square-0.17 \square-0.01 \square^{*}$ & $0.23 \square 0.01 \square 0.46 \square^{*}$ & $-0.03 \square-0.08 \square 0.03 \square$ \\
\hline PWA & $0.15 \llbracket 0.06 \sqcap 0.23 \rrbracket^{*}$ & $0.15 \square 0.05 \square 0.25 \square^{*}$ & $-0.01 \llbracket-0.14 \llbracket 0.12 \llbracket$ & $0.05 \square 0.0100 .10 \square^{*}$ & $0.02 \square-0.07 \square 0.10 \square$ & $-0.07 \square-0.13 \square-0.01 \square^{*}$ & $0.17 \square 0.09 \llbracket 0.26 \square^{*}$ & $-0.02 \llbracket-0.05 \llbracket 0.02 \square$ \\
\hline TD & $-0.15 \square-0.24 \square-0.06 \square{ }^{*}$ & $-0.23 \square-0.47 \llbracket 0.01 \square$ & $0.08 \square-0.17 \llbracket 0.33 \square$ & $-0.22 \llbracket-0.42 \llbracket-0.02 \square^{*}$ & $-0.01 \llbracket-0.08 \llbracket 0.05 \square$ & $0.04 \llbracket 0.01 \square 0.09{ }^{*}$ & $-0.09 \square-0.14 \rrbracket-0.04 \square *$ & $0.04 \rrbracket-0.12 \llbracket 0.20 \rrbracket$ \\
\hline ATHWR & $-0.25 \square-0.33 \square-0.17 \square^{*}$ & $-0.17 \square-0.39 \llbracket 0.02 \square$ & $-0.08 \square-0.29 \square 0.15 \square$ & $-0.09 \llbracket-0.19 \llbracket 0.01 \square$ & $0.01 \square-0.06 \square 0.06 \square$ & $0.10 \sqsubset 0.01 \square 0.19 \llbracket *$ & $-0.21 \square-0.41 \square-0.02 \square *$ & $0.02 \square-0.03 \llbracket 0.08 \rrbracket$ \\
\hline AIS & $0.15 \llbracket 0.08 \square 0.22 \square^{*}$ & $0.05 \square-0.09 \llbracket 0.18 \square$ & $0.11 \square-0.06 \llbracket 0.27 \square$ & $0.11 \llbracket 0.02 \llbracket 0.19{ }^{*}$ & $0.01 \square-0.01 \square 0.03 \square$ & $-0.11 \square-0.18 \square-0.03 \square^{*}$ & $0.14 \llbracket 0.07 \square 0.21 \square^{*}$ & $-0.10 \square-0.23 \llbracket 0.03 \square$ \\
\hline PHOS & $0.18 \square 0.10 \unrhd 0.26 \square^{*}$ & $0.14 \llbracket 0.03 \square 0.26 \square^{*}$ & 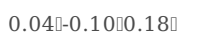 & $0.03 \square 0.01 \square 0.06 \square^{*}$ & $0.01 \square-0.01 \square 0.01 \square$ & $-0.06 \square-0.110-0.010^{*}$ & $0.20 \square 0.07 \square 0.32 \square^{*}$ & $-0.02 \square-0.06 \square 0.02 \square$ \\
\hline
\end{tabular}

Abbreviations: GSR, green space ratio; GCR, green coverage ratio; TGCR, tree green cover ratio; PWA, percentage of water area; TD, trail density; ATHWR, average trail height to width ratio; AIS, average intersection spacing; PHOS, percentage of hard open space; I, Illumination; RH, Relative Humidity; HSI, Heat Stress Index; NOI, Negative Oxygen Ions; $\mathbf{P M}_{2.5}$, Fine Particulate Matter. A separate mediation model was fitted for each greenspace measure and each potential mediator. Independent indirect paths were tested. Standardized regression coefficients and $95 \%$ CIs are reported. a, adjusted for age and education. $*, \mathbf{p}<0.05$. 
Table 9 Results of regression analysis of relationships between adjusted landscape elements, environmental factors and public health variables

\begin{tabular}{|c|c|c|c|c|c|c|c|c|}
\hline \multirow[t]{2}{*}{ Outcome } & \multirow[t]{2}{*}{ Mediators } & $\begin{array}{l}\text { Model 1: GSR - } \\
\text { SFTOTAL }\end{array}$ & $\begin{array}{l}\text { Model 2:GCR- } \\
\text { SFTOTAL }\end{array}$ & $\begin{array}{l}\text { Model 3: } \\
\text { PWA-SFTOTAL }\end{array}$ & $\begin{array}{l}\text { Model 4:TD- } \\
\text { SPTOTAL }\end{array}$ & $\begin{array}{l}\text { Model } \\
\text { 5:ATHWR- } \\
\text { SFTOTAL } \\
\end{array}$ & $\begin{array}{l}\text { Model 6:AIS- } \\
\text { SFTOTAL }\end{array}$ & $\begin{array}{l}\text { Model 7:PHOS- } \\
\text { SFTOTAL }\end{array}$ \\
\hline & & \multicolumn{7}{|c|}{ Coef. $\left(R^{2}, S E\right)$} \\
\hline SFTOTAL & - & $0.23(0.21,0.05) \cdots$ & $0.25(0.22,0.04)^{* * *}$ & $0.15(0.18,0.04)^{* * *}$ & $-0.15(0.18,0.04) * * *$ & $-0.25(0.22,0.04)^{* * *}$ & $0.15(0.18,0.04)^{* * *}$ & $0.18(0.19,0.04)^{* * *}$ \\
\hline I & - & $-0.38(0.16,0.04) \cdots$ & $-0.38(0.16,0.04) * * *$ & $-0.28(0.09,0.05)^{* * *}$ & $0.90(0.82,0.02)^{* * *}$ & $0.54(0.30,0.04)^{* * *}$ & $-0.48(0.24,0.04)^{* * *}$ & $-0.13(0.03,0.05)^{* *}$ \\
\hline RH & - & $0.27(0.08,0.05) \cdots$ & $0.42(0.17,0.04)^{* * *}$ & $0.63(0.40,0.04)^{* * *}$ & $-0.60(0.36,004)^{* * *}$ & $-0.52(0.28,004) * * *$ & $0.12(0.02,0.05) *$ & $0.08(0.01,0.05)$ \\
\hline HSI & - & $-0.64(0.42,0.04) \cdots$ & $-0.46(0.22,0.04) * * *$ & $-0.33(0.12,0.05)^{* * *}$ & $0.20(0.05,0.05)^{* * *}$ & $0.54(0.31,004)^{* * *}$ & $-0.40(0.17,0.04)^{* * *}$ & $-0.30(0.10,0.05)^{* * *}$ \\
\hline NOI & - & $0.86(0.73,002) \cdots$ & $0.85(0.72,0.03)^{* * *}$ & $0.51(0.26,004)^{* * *}$ & $-0.26(0.06,0.05)^{* * *}$ & $-0.81(0.66 .0 .03)^{* * *}$ & $0.46(0.21,0.04)^{* * *}$ & $0.68(0.45,0.04)^{* * *}$ \\
\hline PM2.5 & - & $0.17(0.06 .0 .05) \cdots$ & $0.30(0.12,0.05)^{* * *}$ & $0.18(0.06 .005)^{* * *}$ & $-0.83(0.84,0.03)^{* * *}$ & $0.33(0.14,0.04)^{* * *}$ & $0.48(0.26 .004)^{* * *}$ & $0.20(0.07,0.05)^{* * *}$ \\
\hline \multirow{6}{*}{ SFTOTAL } & - & $0.04(0.24,0.09)$ & $0.05(0.24,0.08)$ & $-0.01(0.24,0.07)$ & $0.08(0.24,0.13)$ & $-0.08(0.24,0.11)$ & $0.11(0.24,0.08)$ & $0.04(0.24,0.07)$ \\
\hline & I & $-0.19(0.24,0.08)^{\circ}$ & $-0.19(0.24,0.08)^{*}$ & $-0.20(0.24,0.08) *$ & $-0.24(0.24,011) *$ & $-0.16(0.24,0.10)$ & $-0.22(0.24,0.09)^{* *}$ & $-0.21(0.24,0.09)^{*}$ \\
\hline & RH & $0.03(0.24,0.06)$ & $0.02(0.24,0.06)$ & $0.03(0.24,008)$ & $0.02(0.24,006)$ & $0.01(0.24,0.06)$ & $0.09(0.24,0.08)$ & $0.03(0.24,0.06)$ \\
\hline & HSI & $0.21(0.24,0.08) *$ & $0.19(0.24,0.09) *$ & $0.21(0.24,0.08) *$ & $0.21(0.24,0.08)^{* *}$ & $0.18(0.24,0.08) *$ & $0.27(0.24,0.09)^{* *}$ & $0.20(0.24,0.08) *$ \\
\hline & NOI & $0.29(0.24,0.1) \cdots$ & $0.28(0.24,0.13) *$ & $0.33(0.24,007) * * *$ & $0.34(0.24,007) * * *$ & $0.26(0.24,011) *$ & $0.30(0.24,0.07)^{* * *}$ & $0.29(0.24,0.09)^{* *}$ \\
\hline & PM2.5 & $-0.09(0.24,0.09)$ & $-0.09(0.24,0.09)$ & $-0.09(0.24,0.10)$ & $-0.05(0.24,010)$ & $-0.07(0.24,0.09)$ & $-0.21(0.24,0.13)$ & $-0.11(0.24,0.10)$ \\
\hline
\end{tabular}

\subsection{Mediation analysis}

\subsubsection{Mediation effects of greenness on public health by physical environmental factors}

Results of modeling with GSR and GCR as independent variables, I, RH, $\mathrm{HSI}, \mathrm{NOI}$, and $\mathrm{PM}_{2.5}$ as mediating variables, total health score (SFTOTAL) as the dependent variable, and age and education as covariates, with bootstrapping tests of mediation effects, are shown in Table 7, Table 8, and Figure 6.

Regression analysis showed that GSR had a positive effect on SFTOTAL $(\beta=0.23, t=4.88, p<0.001 ;$ Table 8$)$. Wen environmental factors were added as mediating variables, the direct effect of GSR on SFTOTAL was not significant $(\beta=0.04, t=0.44, p=0.6615)$. However, effects of GSR on SFTOTAL through I $(\beta=-0.19, t=-2.24, p<0.05), H S I(\beta=0.21, t=2.64$, $p<0.05)$, and NOI $(\beta=0.29, t=2.96, p<0.01)$ were significant, and none of the corresponding $95 \%$ confidence intervals contained 0 , indicating significant mediating effects, with effect values of $0.07,-0.13$, and 0.25 , respectively. The environmental factors' mediation of GSR's effects on SFTOTAL decrease in the order NOI>HSI>|>PM $2.5>\mathrm{RH}$, indicating that GSR's effects on public health are mainly mediated through effects on the acoustic, thermal, and light environments.

GCR had a positive effect on SFTOTAL $(\beta=0.25, t=5.77, p<0.001)$, but when environmental factors were added as mediating variables the direct effect of GCR on SFTOTAL was not significant $(\beta=0.05, t=0.40, p=0.6886)$. Its overall mediating effect though physical environmental factors was also insignificant. However, GCR had significant effects through I $(\beta=-0.19, t=-2.26, p<0.05), \mathrm{HSI}(\beta=0.19, t=2.19, p<0.05)$, and $\mathrm{NOI}(\beta=0.28, t=2.11, p<0.05)$, with effect values of $0.07,-0.09$, and 0.23 , respectively. This suggests that GCR mainly affects public health through I, HSI, and NOI, probably with contributions from other mediators that require elucidation.

Taken together, although GCR did not play a significant role in the total mediating effect of the considered environmental factors, I, HSI, and NOI were significant mediators of effects of both greenness indicators, indicating that greenness affects public health mainly through its effects on the light, thermal, and atmospheric environments of the focal highdensity urban neighborhoods.

\subsubsection{Mediation effects of blue space on public health by physical environmental factors}


Results of modeling with PWA as the independent variable, I, RH, HSI, NOI, and $\mathrm{PM}_{2.5}$ as mediating variables, total health score (SFTOTAL) as the dependent variable, and age and education as covariates, with bootstrapping tests of mediation effects, are also shown in Table 7, Table 8, and Figure 6. They show that PWA had a positive effect on SFTOTAL ( $\beta=0.15$, $t=3.38, p<0.001)$. When environmental factors were added as mediating variables, the direct effect of PWA on public health was not significant $(\beta=-0.01, t=-0.11, p=0.915)$. However, it had significant effects through I $(\beta=-0.20, t=-2.33$, $p<0.05), \mathrm{HSI}(\beta=0.21, t=2.51, p<0.05)$, and $\mathrm{NOI}(\beta=0.33, t=4.54, p<0.001)$, with effect values of $0.05,-0.07$, and 0.17 , respectively. The environmental factors' mediation of PWA's effects on SFTOTAL decrease in the order $\mathrm{NOI}>\mathrm{HSI}>\mathrm{I}>\mathrm{RH}>\mathrm{PM}_{2.5}$, indicating that $\mathrm{NOI}$, I and HSI are the main mediators of blue spaces' effects on public health. These findings indicate that in neighborhoods of high-density cities, blue spaces mainly affect public health through atmospheric, light and thermal environments.

\subsubsection{Mediation effects of walking trail systems on public health by physical environmental factors}

Results of modeling with TD, ATHWR, and AIS as independent variables, I, RH, $\mathrm{HSI}, \mathrm{NOI}$, and $\mathrm{PM}_{2.5}$ as mediating variables, total health score (SFTOTAL) as the dependent variable, and age and education as covariates, with bootstrapping tests of mediation effects, are also shown in Table 7, Table 8, and Figure 6. They show that TD had a negative effect on SFTOTAL $(\beta=-0.15, t=-3.42, p<0.001)$, but when environmental factors were added as mediating variables, the direct effect was not significant $(\beta=0.08, t=0.66, p=0.5107)$, while the direct effect on public health through I $(\beta=-0.24, t=-2.20, p<0.05), H S I$ $(\beta=0.21, t=2.64, p<0.05)$, and NOI $(\beta=0.34, t=5.11, p<0.001)$ had a significant effect on public health.

The overall mediating effect of the considered physical environment factors was not significant either. However, the effects through I $(\beta=-0.24, t=-2.20, p<0.05), \mathrm{HSI}(\beta=0.21, t=2.64, p<0.05)$, and $\mathrm{NOI}(\beta=0.34, t=5.11, p<0.001)$ were significant, with effect values of $-0.22,0.04$, and -0.09 , respectively. In summary, TD affects public health through effects on light, thermal and acoustic environments, but the environmental factors had no significant overall mediating effect, and other factors likely contribute.

ATHWR had a negative effect on SFTOTAL $(\beta=-0.25, t=-5.94, p<0.001)$, but when environmental factors were added as mediating variables, the direct effect was not significant $(\beta=-0.08, t=-0.7, p=0.4863)$. The overall mediating effect through physical environment factors on public health was not significant either. However, ATHWR had significant effects through $\mathrm{HSI}(\beta=0.18, t=2.14, p<0.05), \mathrm{NOI}(\beta=0.26, t=2.24, p<0.05)$, suggesting that it affects public health through the thermal and acoustic environments, probably with contributions from other mediating factors.

AIS had a positive effect on SFTOTAL $(\beta=0.15, t=3.48, p<0.001)$. Again, when environmental factors were added as mediating variables the direct effect of AIS on public health was not significant $(\beta=0.11, t=1.33, p=0.1856)$, and the overall mediating effect of physical environmental factors was not significant either. However, ASI had significant effects through I $(\beta=-0.22, t=-2.60, p<0.05), \mathrm{NOI}(\beta=0.30, t=4.50, p<0.001)$, and $\mathrm{HSI}(\beta=0.27, t=2.92, p<0.05)$, with effect values of 0.11 , -0.11 , and 0.14 , respectively. The results indicate that overall effects of AIS through the combined physical environment factors are insignificant, but it has significant effects mediated through light, acoustic and thermal environments, probably with contributions from other mediating factors.

Taken together, none of the three indicators of the walking trail system had significant effects on public health mediated through the combined physical environment factors. However, effects mediated through I, HSI, and NOI were significant. These findings indicate that in neighborhood environments of high-density cities walking trail systems have effects on public health mediated through the light, thermal, and atmospheric environments, probably in combination with other mediating factors and influence pathways that warrant further exploration and confirmation.

\subsubsection{Mediation effects of hard open space on public health by physical environmental factors}


Results of modeling with PHOS as the independent variable, I, RH, HSI, NOI, and PM2.5 as mediating variables, SFTOTAL as the dependent variable, and age and education as covariates, with mediation effects tested by bootstrapping are also shown in Table 7, Table 8, and Figure 6. They show that PHOS had a positive effect on public health $(\beta=0.18, t=4.16$, $p<0.001)$, but again when environmental factors were added as mediating variables, the direct effect of PHOS on public health was not significant $(\beta=0.04, t=0.52, p=0.6065)$. However, it had significant effects through I $(\beta=-0.21, t=-2.39$, $p<0.05), \mathrm{HSI}(\beta=0.20, t=2.58, p<0.05)$, and $\mathrm{NOI}(\beta=0.29, t=3.27, p<0.05)$, with effect values of $0.03,-0.06$, and 0.20 , respectively. The mediating effects of $\mathrm{PHOS}$ on public health are, in descending order, $\mathrm{NOI}>\mathrm{HSI}>\mathrm{I}>\mathrm{PM} 2.5>\mathrm{RH}$. These results indicate that effects of hard open spaces on public health are mainly mediated through the atmospheric, thermal and light environments.

\section{Discussion}

\subsection{The neighborhood landscape elements and physical environmental factors of high-density cities with subtropical monsoon climate are closely related to public health}

The presented results corroborate our previous findings ${ }^{[29]}$ that the physical environmental factors of neighborhoods are strongly associated with public health in high-density cities with subtropical monsoon climates (Table 6), and strengths of the detected associations are largely consistent with previous studies, except for those of atmospheric and acoustic environmental factors.

In contrast to the previous study, in which we found no significant association between atmospheric environment and public health, in this study we found a significant positive association between negative oxygen ions in the atmosphere and public health. This is consistent with previous findings by other scholars that negative oxygen ions in the air have positive effects on health, including stress relief ${ }^{[67]}$, and restoration of physiological responses after exercise ${ }^{[68]}$. Our study also extends findings that they promote public health indoors ${ }^{[69]}$ and in the vicinity of waterfalls in forest areas ${ }^{[70]}$. Reasons for the differences in results between this and our previous study may be related to differences in sampling sites, as we collected data from more neighborhoods, with more significant variations in landscape elements and physical environmental factors, thereby increasing the scope for detecting significant effects of environmental variables. However, in contrast to previous conclusions that the acoustic environment is significantly associated with public health ${ }^{[29]}$, in this study we detected no significant association between acoustic environment and public health. This may be at least partly because the maximum noise level recorded in any of the selected neighborhoods in this study was $62.2 \mathrm{db}$, which is within Chinese environmental standards and well below the general threshold for damage to human health [71]. Moreover, the sampling period was much shorter than in some previous studies and may have been too short to detect cumulative longer-term associations with public health ${ }^{[72]}$. Thus, according to these hypotheses the findings suggest that the acoustic environment may have long-term rather than short-term effects on human health.

The results of this study clearly support our main hypothesis, that indicators of some landscape elements of the neighborhoods, including greenness (GSR and GCR), blue space (PWA), walking trail system (TD, ATHWR, and AIS), and hard open space (PHOS) are significantly correlated with public health in Guangzhou, and probably other high-density cities with a subtropical monsoon climate (Table 5). However, garden architecture (PGA), sports spaces (PSS), and the tree cover component of greenness (TGCR) were not significantly correlated with total, physiological or psychological health scores.

Of the landscape elements associated with public health, we found that GSR and GCR (reflecting vegetation elements), and water elements, are positively associated, in accordance with findings of many previous studies ${ }^{[73-75]}$ that increases in greenness and blue spaces in neighborhoods promote public health, both generally and in high-density cities. We also found that GCR (the green coverage ratio) had a higher correlation coefficient than the green space ratio (GSR) and may 
thus warrant higher prioritization in the planning and renewal of high-density urban neighborhoods with tight land constraints. Two parameters of the walking trail system, the trail density (TD) and average trail height to width ratio (ATHWR), were negatively associated and one (average intersection spacing, AIS) was positively associated with public health. As high ATHWR values imply narrow trail spaces, these findings indicate that trails that are too narrow do not promote health. It has been suggested that higher trail densities imply better accessibility and thus promote healthy physical activity for residents ${ }^{[76]}$, but our results suggest the opposite. Other studies by Chinese scholars have concluded that in China increases in trail densities may sometimes be beneficial, but excessively high densities reduce activity distances to the detriment of health ${ }^{[77]}$. The positive association between average intersection spacing (AIS) and public health suggests that in high-density cities increases in intersection spacing may increase residents' activity distances and thus promote health. This may also explain why trail density is negatively associated with public health and average intersection spacing positively associated with public health in high-density cities. The reasons for this and the mechanisms involved warrant more detailed attention. As already mentioned, these landscape elements are closely related to public health and thus should be considered when renewing high-density urban neighborhoods.

For landscape elements that were not significantly associated with public health, there were several possible interpretations. One was the tree green cover ratio (TGCR). We found that several sampling neighborhoods had similar greenness structure, with high TGCR, so relatively small variation in the ratio may partly explain its lack of association with public health. Alternatively, the structure of neighborhood greenness may not be a major public health factor. A forest with a rich canopy structure may provide more ecological services and aesthetic values than other forms of vegetation [78]. However, due to light and space constraints it is difficult to create such structures in high-density neighborhoods, in which shrubs and groundcover can provide more greenery from a human perspective. Thus, we need more refined and detailed empirical data regarding the association between this indicator and public health. Similarly, previous studies have shown that good quality landscape architecture and sports spaces promote physical activity ${ }^{[79]}$ and health ${ }^{[80]}$, but we found no significant association between public health and the indicators of either of these landscape elements. We hypothesize that this may be because the landscape architecture and sports spaces in the focal high-density neighborhoods have conventional generic designs that do not match characteristics of the sites, have poor quality and are not attractive. Thus, they may have low usage and functionality. If so, adopting generic designs in high-density neighborhoods may be inappropriate, and the design of suitable landscape architecture and sports spaces for such neighborhoods requires more attention.

\subsection{Neighborhood landscape elements have public health effects mediated by the physical environmental factors}

Results of this study also show that greenness (GSR), blue spaces, and hard open spaces-but not the green coverage ratio (GCR) or walking trail system parameters-significantly influence public health through the integrated effects mediated by environmental factors, in partial accordance with our main hypothesis (Table 7, Table 8 and Figure 6). However, detailed examination of the mediating effects of the physical environment, light environment, thermal environment, and atmospheric environment (particularly NOI) provide further illumination of the mechanisms involved.

Despite the difference in environmental factors' overall mediation on the effects of GSR and GCR, I, HSI, and NOI had significant mediating effects in both cases. These findings are consistent with those of previous authors and suggest that greenness can influence health by mitigating heat exposure ${ }^{[81]}$ and increasing negative ion concentrations ${ }^{[69]}$. They also show that GSR and GCR can effectively reduce daytime illumination and provide welcome shade in high-density subtropical cities like Guangzhou that are consistently hot, and thus positively correlate with public health. GCR may also contribute to health-promoting processes and phenomena such as stress recovery and social cohesion ${ }^{[82]}$, which require more attention both generally and in high-density cities particularly. 
Blue spaces positively influence public health through a combination of physical environmental factors, mainly the light environment (I), thermal environment ( $\mathrm{HSI})$, and atmospheric environment (NOI). The results confirm findings in other settings that blue spaces can increase negative oxygen ion concentrations ${ }^{[70]}$ and mitigate thermal exposure ${ }^{[83]}$ in neighborhoods of high-density cities. We hypothesize that the health-promoting negative association between blue space and illumination is due to the presence of greenery around water bodies in the focal neighborhoods, which highlights the mediating interactions between PWA and I. As a side note, when blue spaces are installed in neighborhoods, the configuration of vegetation can improve public health benefits through its effects on the light environment. In addition, blue space and greenness can jointly mitigate discomfort caused by high temperatures ${ }^{[84]}$. However, the lower impact effect of the blue space element compared to the greenness suggests that it has lower public health benefits, and it has also been shown that blue spaces are less effective and more expensive than greenness for mitigating heat island effects and providing ecological value ${ }^{[85]}$. T Therefore, when blue spaces cannot be installed in high-density neighborhoods or budgets are limited, installing greenness may be a good alternative..

Regarding the walking trail system, although the total mediated effect was not significant, its indicators were significantly correlated with public health (SFTOTAL), and had consistently significant effects mediated by I, HSI, and NOI (except for an insignificant effect of ATHWR mediated by I). Both the trail density (TD) and average trail height to width ratio (AWHWR) were positively associated with I and HSI in the neighborhoods, and negatively associated with the NOI concentration, thus they had negative effects on public health. This is because in communities with high green space and green coverage dense trails and narrow trail spaces can squeeze green spaces, resulting in inability to plant shade plants and provide shade facilities, thereby reducing negative oxygen ion concentrations, and increasing both sunlight and adverse thermal effects ${ }^{[86]}$. In contrast, the average intersection spacing (AIS) in a neighborhood has the opposite impact on public health. In summary, dense walking trail systems and narrow trail spaces in high-density urban neighborhoods are detrimental to health-promoting physical environmental factors, and although some scholars have concluded that trail systems promote health through mediators such as physical activity ${ }^{[36,87]}$, this may not be applicable in high-density cities in China ${ }^{[77]}$, and more research is needed to elucidate the relationships.

Hard open spaces are distinct spaces from landscape architecture and dedicated sports spaces that provide Chinese residents with places for recreation and social activities ${ }^{[88]}$. In a subtropical high-density city, the mechanism mediating its influence on public health through the physical environment is similar to that of greenness elements, suggesting that to some extent the area of hard open space in a community positively influences public health through the physical environment. However, the difference is that hard open spaces are only associated with physical health, probably because their effect is not mediated solely through the physical environment, but also through another link (promotion of physical activity) to the physical environment ${ }^{[79]}$.

In summary, in high-density urban neighborhoods, effects of the abovementioned landscape elements on public health are mainly mediated through the light, thermal, and atmospheric environments.

\subsection{Two unexpected discoveries contrary to experience}

Two results of the study were contrary to everyday experience. The first is that greenness elements did not affect public health through $\mathrm{PM}_{2.5}$ and they were positively correlated with $\mathrm{PM}_{2.5}$ (Tables 5 and 8), in contrast to findings of most studies that vegetation can adsorb and reduce levels of atmospheric pollutants ${ }^{[89,90]}$. This may be because the aerodynamic dilution of pollutants is more effective in the focal sites than the adsorption of air pollutants by vegetation, while excessive vegetation reduces ventilation and thus promotes increases in aerial concentrations of the pollutants [91],

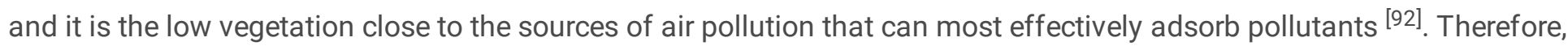
in some cases, trees in a neighborhood may reduce rather than improve air quality ${ }^{[75]}$. This would explain why greenness elements can be positively associated with $\mathrm{PM}_{2.5}$ in neighborhoods of high-density cities. Our results indicate that such a 
situation does not affect public health, so they do not refute the view that the overall effects of greenness elements promote public health. If potential adverse effects require mitigation, vegetation designs with excessive enclosure should be avoided in high-density communities and ventilation can be enhanced by regular pruning of trees.

The other result that conflicted with everyday experience is that in the hot and humid climate of Guangzhou relative humidity had a weak positive association with health rather than a negative effect on residents ${ }^{[19]}$ (Table 5). Probably because the relative humidity in the neighborhoods was within the acceptable range for Guangzhou residents (less than $78 \%$ ) during the sampling period ${ }^{[93]}$. In contrast, landscape elements did not affect public health through humidity, indicating that despite a strong positive association of blue spaces with relative humidity, the humidity environment of the community was mainly influenced by the overall environment of the urban area ${ }^{[94]}$.

\subsection{Insights into regeneration planning for high-density urban communities in subtropical monsoon climates}

Synthesizing the above results and discussion, we propose the following recommendations for regeneration strategies for high-density urban neighborhoods of cities with subtropical monsoon climates from the perspective of physical environment and public health.

Q1هMaximizing green and blue spaces promotes public health, but green space is more effective and economical than blue space, and the effectiveness of blue spaces is enhanced by vegetation elements, so green spaces should be prioritized in high-density neighborhoods.

Q2ХUse of trees in moderation, with more small shrubs and ground cover (to adsorb dust and pollutants from roads and traffic), is recommended. Selected trees should have good top cover and sufficiently high branches to provide shade and thus reduce both illumination and heat stress. They should also be regularly pruned to provide good ventilation. Various forms of vertical and rooftop greenery can also be used to increase the amount of green in neighborhoods.

$\triangle 3 \llbracket$ Avoid dense trails by adopting wider intersection spacing and greater trail height to width ratios. In large-scale renovations of neighborhoods appropriate reductions in both the trail density and trail height to width ratio, with increases in the intersection spacing, may be beneficial. In micro-renovations, installation of vertical greenery or removable shade devices in the trails to weaken the negative impact of a dense trail system on the physical environment and public health may also promote public health.

\4囚Utilize unused spaces by transforming them into open hard spaces, concentrated (as far as possible) in the neighborhood. If high density prevents this, unused space or gray corner space can be converted into open hard spaces to provide leisure and recreational places for residents, while reducing the density and height to width ratio of the neighborhood trails.

\5खLandscape architecture and dedicated sports spaces should be tailored to match characteristics and needs of the local communities, with due consideration of demographic profiles and preferences etc. For example, neighborhoods with high numbers of children should adopt bright colors and child-oriented designs, while neighborhoods with more elderly people should use more neutral colors and age-appropriate designs. In addition, customized (or at least carefully selected appropriate designs) should be used instead of standard generic designs so that facilities are attractive for residents and effectively provide public health services.

\6खNeighborhood landscape renewal initiatives should include improvement of effects of landscape elements on the light, thermal and atmospheric environments, all of which are important mediators of the elements' effects on public health. The acoustic environment, humidity and particulate air pollution can also be improved through appropriate neighborhood operation and management, physical spraying and drying, and enhanced ventilation. 
$\triangle 7 \llbracket$ As shown by data in Tables 7 and 8, landscape elements in neighborhoods should be prioritized in renewal initiatives in the following order: greenness $>$ hard open space $>$ blue space $>$ walking trail system > sports space $>$ landscape architecture.

\subsection{Limitations and Future Research}

Several limitations of this study should be acknowledged. First, our study was based on a cross-sectional survey and mediation analysis to examine the associations between landscape elements, physical environmental factors, and public health. This also provided indications of the mechanisms involved, but it is not sufficient for thorough elucidation of the mechanisms of dynamic changes in effects of landscape elements and environmental factors on public health over time. Therefore, longitudinal follow-up and/or experimental studies are also required. Second, the study relied on random sampling and therefore afforded limited analysis of the correlations between landscape elements and public health. Future studies would benefit from systematic sampling and/or larger samples. Finally, we focused solely on mechanisms mediating effects of landscape elements on public health that solely involve physical environmental factors, which cannot fully explain the relations. Other factors (such as physical activity, stress recovery, and social cohesion) are known to have mediating effects ${ }^{[5,30,32]}$. Thus, future studies should explore the influence of specific landscape elements on public health through multiple parallel mediators or chains of mediators in more detail, with as full as possible consideration of the dynamic interactions involved.

\section{Conclusion}

We have investigated associations between neighborhood landscape elements and public health in a high-density city in a subtropical monsoon region (Guangzhou), and obtained indications of the mediating pathways through physical environmental factors involved. Specifically, we found associations between public health and greenness, blue spaces, walking trail systems, hard open spaces, landscape architecture, and sports spaces. We also detected multiple mediating effects of thermal, humidity, wind, atmospheric, light, and acoustic environments.

The results showed that greenness, blue spaces, and hard open spaces were positively associated with public health, and the average intersection spacing in the walking trail system was positively associated (while trail density and the average trail height to width ratio were negatively associated) with public health. No association was found between landscape architecture or sports spaces and public health. A multiple mediating effects test proved that greenness, blue spaces, and hard open spaces affect public health through the physical environment, mainly through effects on light, thermal, and atmospheric environments. The walking trail system exerts effects through a similar mechanism, but also likely has other mediators. The results show that neighborhood landscape elements affect public health mainly through light, thermal, and atmospheric environments, extending insights into the mechanisms involved and providing suggestions for improving neighborhood renewal initiatives in subtropical high-density cities.

\section{List Of Abbreviations}




\begin{tabular}{|l|l|}
\hline abbreviations & Full name \\
\hline SF-36 & the 36-item health scale \\
\hline BP & Body Pain \\
\hline PF & Physical Functioning \\
\hline RP & Role-Physical \\
\hline GH & General Health \\
\hline VT & Vitality \\
\hline SF & Social Functioning \\
\hline RE & Role-Emotional \\
\hline MH & Mental Health \\
\hline HT & Reported Health Transition \\
\hline N & Noisiness \\
\hline I & Illumination \\
\hline AWS & Average Wind Speed \\
\hline RH & Relative Humidity \\
\hline HSI & Heat Stress Index \\
\hline NOI & Negative Oxygen Ions \\
\hline PM2.5 & Fine Particulate Matter \\
\hline HI1 & Physical Component Summary score \\
\hline HI2 & Mental Component Summary score \\
\hline GSR & green space ratio \\
\hline GCR & green coverage ratio \\
\hline TGCR & tree green cover ratio \\
\hline PWA & percentage of water area \\
\hline TD & trail density \\
\hline ATHWR & average trail height to width ratio \\
\hline AIS & average intersection spacing \\
\hline PHOS & \\
\hline PGA & percentage of hard open space \\
\hline PSS & percentage of garden architecture area sports space area \\
\hline
\end{tabular}

\section{Declarations}

Ethics approval and consent to participate]Not applicable.

Consent for publicationINot applicable.

Availability of data and materialsロThe datasets generated and/or analysed during the current study are not publicly available due [The data is still used for future research and will not be disclosed for the time being.] but are available from the corresponding author on reasonable request.

Competing interests: The authors declare that they have no competing interests.

Funding: the National Natural Science Foundation of China, grant number 51708227, funded this research.

Author Contributions: Conceptualization, W.G. and Y.F.; methodology, Q.Q.; software, Q.Q.; validation, Y.F.,

R.T. and Y.L.; formal analysis, Y.F.; investigation, Y.L., R.T. and Y.F.; data curation, Y.F. and R.T.; writing-original draft preparation, W.G. and Y.F.; writing-review and editing, W.G.; visualization, Y.F.; supervision, W.G.; project administration, Y.F.; funding acquisition, W.G. All authors have read and agreed to the published version of the manuscript. 
Acknowledgements: Not applicable.

\section{References}

1. Hamlin C, Sheard S. Revolutions in public health: 1848, and 1998?[J]. BMJ (Clinical research ed.), 1998, 317(7158): 587-591. doi: 10.1136/bmj.317.7158.587.

2. WHO. Preventing Disease through Healthy Environments: A Global Assessment of the Burden of Disease from Environmental Risks.2016. Available online: https://www.who.int/publications/i/item/9789241565196 (accessed on 3 February 2021).

3. WHO. Promoting Health: Guide to National Implementation of the Shanghai Declaration, 11-13. 2018. Available online: https://www.who.int/publications/i/item/WHO-NMH-PND-18.2 (accessed on 3 February 2021).

4. Helbich M, Yao Y, Liu Y, et al. Using deep learning to examine street view green and blue spaces and their associations with geriatric depression in Beijing, China[J]. ENVIRONMENT INTERNATIONAL. 2019;126:107-17. doi:10.1016/j.envint.2019.02.013.

5. Liu Y, Wang R, Grekousis G, et al. Neighbourhood greenness and mental wellbeing in Guangzhou, China: What are the pathways?[J]. LANDSCAPE AND URBAN PLANNING, 2019,190(103602). doi:10.1016/j.landurbplan.2019.103602.

6. Su M, Tan Y, Liu Q, et al. Association between perceived urban built environment attributes and leisure-time physical activity among adults in Hangzhou, China[J]. PREVENTIVE MEDICINE. 2014;66:60-4.

doi:10.1016/j.ypmed.2014.06.001.

7. Roux AVD, Mair C. Neighborhoods and health[M]. Annals of the New York Academy of Sciences. 2010:125-145. doi: 10.1111/j.1749-6632.2009.05333.x.

8. Halonen JI, Hansell AL, Gulliver J, et al. Road traffic noise is associated with increased cardiovascular morbidity and mortality and all-cause mortality in London[J]. Eur Heart J. 2015;36(39):2653-61. doi:10.1093/eurheartj/ehv216.

9. Bowling A. Do perceptions of neighbourhood environment influence health? Baseline findings from a British survey of aging[J]. Journal of Epidemiology Community Health. 2006;60(6):476-83. doi:10.1136/jech.2005.039032.

10. Lercher P, Evans GW, Meis M, et al. Ambient neighbourhood noise and children's mental health[J]. OCCUPATIONAL AND ENVIRONMENTAL MEDICINE. 2002;59(6):380-6. doi:10.1136/oem.59.6.380.

11. Van Renterghem T. Towards explaining the positive effect of vegetation on the perception of environmental noise[J]. Urban Forestry Urban Greening. 2019;40:133-44. doi:10.1016/j.ufug.2018.03.007.

12. Buman MP, Hekler EB, Haskell WL, et al. Objective Light-Intensity Physical Activity Associations With Rated Health in Older Adults[J]. Am J Epidemiol. 2010;172(10):1155-65. doi:10.1093/aje/kwq249.

13. Beute F, de Kort YAW. Salutogenic effects of the environment: review of health protective effects of nature and daylight.[J]. Applied psychology: Health well-being, 2014,6(1):67-95. doi:10.1111/aphw.12019.

14. Chen LS. The impact of light pollution on the environment and health [J]. Chinese Tropical Medicine. 2007;7(6):1005-9. doi:CNKI:SUN:RDYX.0.2007-06-079.

15. Gallagher RP, Lee TK. Adverse effects of ultraviolet radiation: A brief review[J]. Prog Biophys Mol Biol. 2006;92(1):119-31. doi:10.1016/j.pbiomolbio.2006.02.011.

16. Huynen MMTE, Martens P, Schram D, et al. The impact of heat waves and cold spells on mortality rates in the Dutch population[J]. Environ Health Perspect. 2001;109(5):463-70. doi:10.2307/3454704.

17. Howe PD, Marlon JR, Wang X, et al. Public perceptions of the health risks of extreme heat across US states, counties, and neighborhoods[J]. Proceedings of the National Academy of Sciences, 2019,116(14):6743-6748. doi: 10.1073/pnas.1813145116.

18. Lugo-Amador NM, Rothenhaus T, Moyer P. Heat-related illness[J]. EMERGENCY MEDICINE CLINICS OF NORTH AMERICA, 2004,22(2):315. doi: 10.1016/j.emc.2004.01.004. 
19. Shaman J, Pitzer VE, Viboud C, et al. Absolute Humidity and the Seasonal Onset of Influenza in the Continental United States[J]. PLOS BIOLOGY, 2010,8(e10003162). doi:10.1371/journal.pbio.1000316.

20. Qi H, Xiao S, Shi R, et al. COVID-19 transmission in Mainland China is associated with tempera- ture and humidity: A time-series analysis[J]. SCIENCE OF THE TOTAL ENVIRONMENT, 2020,728(138778).

doi:10.1016/j.scitotenv.2020.138778.

21. Mendell MJ, Mirer AG, Cheung K, et al. Respiratory and Allergic Health Effects of Dampness, Mold, and DampnessRelated Agents: A Review of the Epidemiologic Evidence[J]. Environmental health perspectives. 2011;119(6):748-56. doi:10.1289/ehp.1002410.

22. Orru $\mathrm{H}$, Maasikmets $\mathrm{M}$, Lai T, et al. Health impacts of particulate matter in five major Estonian towns: main sources of exposure and local differences[J]. Air Quality Atmosphere Health. 2011;4(3-4):247-58. doi:10.1007/s11869-0100075-6.

23. Næss $\emptyset$, Nafstad P, Aamodt G, et al. Relation between Concentration of Air Pollution and Cause-Specific Mortality: Four-Year Exposures to Nitrogen Dioxide and Particulate Matter Pollutants in 470 Neighborhoods in Oslo, Norway[J]. Am J Epidemiol. 2007;165(4):435-43. doi:10.1093/aje/kwk016.

24. Chen $\mathrm{H}$, Kwong JC, Copes $\mathrm{R}$, et al. Exposure to ambient air pollution and the incidence of dementia: A populationbased cohort study[J]. Environment International, 2017,108:271-277. doi: 10.1016/j.envint.2017.08.020.

25. Roberts $\mathrm{S}$, Arseneault $\mathrm{L}$, Barratt $\mathrm{B}$, et al. Exploration of $\mathrm{NO}_{2}$ and $\mathrm{PM}_{2.5}$ air pollution and mental health problems using high-resolution data in London-based children from a UK longitudinal cohort study[J]. Psychiatry Res. 2019;272:817. doi:10.1016/j.psychres.2018.12.050.

26. Jiang S, Ma A, Ramachandran S. Negative Air lons and Their Effects on Human Health and Air Quality Improvement[J]. Int J Mol Sci. 2018;19(10):2966. doi:10.3390/ijms19102966.

27. Baldwin N, Gilani O, Raja S, et al. Factors affecting pollutant concentrations in the near-road environment[J]. Atmos Environ. 2015;115:223-35. 10.1016/j.atmosenv.2015.05.024.

28. Jeong Y, Lee G, Kim S. Analysis of the Relation of Local Temperature to the Natural Environment, Land Use and Land Coverage of Neighborhoods[J]. Journal of Asian architecture building engineering. 2015;14(1):33-40. doi:10.3130/jaabe.14.33.

29. Gao W, Tu R, Li H, et al. In the Subtropical Monsoon Climate High-Density City, What Features of the Neighborhood Environment Matter Most for Public Health?[J]. International Journal of Environmental Research Public Health. 2020;17(24):9566. doi:10.3390/ijerph17249566.

30. Markevych I, Schoierer J, Hartig T, et al. Exploring pathways linking greenspace to health: Theoretical and methodological guidance[J]. Environ Res. 2017;158:301-17. doi:10.1016/j.envres.2017.06.028.

31. Labib SM, Lindley S, Huck JJ. Spatial dimensions of the influence of urban green-blue spaces on human health: A systematic review[J]. ENVIRONMENTAL RESEARCH, 2020,180(108869). doi:10.1016/j.envres.2019.108869.

32. Dzhambov A, Hartig T, Markevych I, et al. Urban residential greenspace and mental health in youth: Different approaches to testing multiple pathways yield different conclusions[J]. Environ Res. 2018;160:47-59. doi:10.1016/j.envres.2017.09.015.

33. Pasanen TP, White MP, Wheeler BW, et al. Neighbourhood blue space, health and wellbeing: The mediating role of different types of physical activity[J]. Environ Int. 2019;131:105016. doi:10.1016/j.envint.2019.105016.

34. Boers S, Hagoort K, Scheepers F, et al. Does Residential Green and Blue Space Promote Recovery in Psychotic Disorders? A Cross-Sectional Study in the Province of Utrecht, The Netherlands[J]. International Journal of Environmental Research Public Health. 2018;15(10):2195. doi:10.3390/ijerph15102195.

35. Roe J, Mondschein A, Neale C, et al. The Urban Built Environment, Walking and Mental Health Outcomes Among Older Adults: A Pilot Study[J]. Frontiers in Public Health, 2020,8. doi:10.3389/fpubh.2020.575946. 
36. Li F. Multilevel modelling of built environment characteristics related to neighbourhood walking activity in older adults[J]. Journal of Epidemiology Community Health. 2005;59(7):558-64. doi:10.1136/jech.2004.028399.

37. Shi S. Important Elements and Features of Neighborhood Landscape for Aging in Place: A Study in Hong Kong[J]. Frontiers in Public Health, 2020,8. doi:10.3389/fpubh.2020.00316.

38. Wu SL, Sun YM. Research on Microclimate Simulation and Improvement Strategies of Streets in Guangzhou Area [J]. Urban Planning Journal, 2016(01):56-62. doi:10.16361/j.upf.201601007.

39. Wang R, Yang B, Yao Y, et al. Residential greenness, air pollution and psychological well-being among urban residents in Guangzhou, China[J]. SCIENCE OF THE TOTAL ENVIRONMENT, 2020,711(134843).

doi:10.1016/j.scitotenv.2019.134843.

40. Chen T, Lang W, Li X. Exploring the Impact of Urban Green Space on Residents' Health in Guangzhou, China[J]. JOURNAL OF URBAN PLANNING AND DEVELOPMENT, 2020,146(050190221). doi: 10.1061/(ASCE)UP.19435444.0000541.

41. Chen C, Luo W, Kang N, et al. Study on the Impact of Residential Outdoor Environments on Mood in the Elderly in Guangzhou, China[J]. Sustainability (Basel Switzerland). 2020;12(9):3933. doi:10.3390/su12093933.

42. Wang R, Liu Y, Lu Y, et al. The linkage between the perception of neighbourhood and physical activity in Guangzhou, China: using street view imagery with deep learning techniques[J]. International Journal of Health Geographics, 2019,18(1). doi:10.1186/s12942-019-0182-z.

43. Guangzhou Municipal Bureau of Statistics. Guangzhou Statistical Yearbook [EB/OL]. Available online: http://112.94.72.17/portal/querylnfo/statisticsYearbook/index. (accessed on 3 February 2021).

44. National Meteorological Science Data Center. Guangdong Surface Climate Data Daily Value Data Set. [EB/OL]. Available online: http://data.cma.cn/data/cdcdetail/dataCode/SURF_CLI_CHN_M UL_DAY_440.html. (accessed on 3 February 2021).

45. Yan XP, Mao JX. The interactive relationship between transportation and land use in high-density development cities: taking Guangzhou as an example [J]. Acta Geographica Sinica, 2004(05):643-652.doi:CNKI:SUN:DLXB.0.2004-05001.

46. Li L, Wang MH, Shen Y. Development and Performance Test of the Chinese Version of SF-36 Health Survey Scale [J]. Chinese Journal of Preventive Medicine. 2002;36(2):109-13. doi:CNKI:SUN:ZHYF.0.2002-02-015.

47. Qiu JC, Xu J, Feng LY, et al. Research on the reliability and validity of SF-36 applied to the health-related quality of life survey of the public servant population in Guangdong Province [J]. Chinese General Practice. 2012;15(04):386-9. doi:CNKI:SUN:QKYX.0.2012-04-014.

48. Ware JEJ, Sherbourne CD. The MOS 36-item short-form health survey (SF-36). I. Conceptual framework and item selection.[J]. Medical care. 1992;30(6):473-83. 10.1097/00005650-199206000-00002.

49. McHorney CA, Ware JEJ, Raczek AE. The MOS 36-Item Short-Form Health Survey (SF-36): II. Psychometric and clinical tests of validity in measuring physical and mental health constructs.[J]. Medical care. 1993;31(3):247-63. doi:10.1097/00005650-199303000-00006.

50. Triguero-Mas M, Dadvand P, Cirach M, et al. Natural outdoor environments and mental and physical health: Relationships and mechanisms[J]. ENVIRONMENT INTERNATIONAL. 2015;77:35-41. doi:10.1016/j.envint.2015.01.012.

51. Qin Y. Research on the Traditional Theory and Inheritance of Chinese Garden Architectural Design [D]. Beijing Forestry University, 2009. Available online:https://kns.cnki.net/KCMS/detail/deta il.aspx?dbname = CDFD0911\&filename = 2009134639.nh. (accessed on 3 February 2021).

52. Ministry of Housing and Urban-Rural Development of China. GB/T 51346 - 2019 Urban green space planning standards GB/T 51346 - 2019[S]. China Construction Industry Press; 2019. 
53. Rui L, Buccolieri R, Gao Z, et al. Study of the effect of green quantity and structure on thermal comfort and air quality in an urban-like residential district by ENVI-met modelling[J]. Build Simul. 2019;12(2):183-94. doi:10.1007/s12273018-0498-9.

54. Liu JP. Urban environmental physics [M]. Beijing: China Construction Industry Press; 2011.

55. Jin WZ, Yu HT. Research on the reliability and validity of SF-36 scale applied to residents' self-health assessment [J]. China Health Resources. 2012;15(3):265-7. doi:CNKI:SUN:WSZY.0.2012-03-040.

56. Zeng WY, Huang BY. Analysis of the reliability and validity of the questionnaire [J]. Statistics Information Forum, 2005,20(6):11-5. doi:CNKI:SUN:TJLT.0.2005-06-001.

57. Wen ZL, Ye BJ. Analysis of Mediation Effect: Method and Model Development [J]. Advances in Psychological Science. 2014;22(05):731-45. doi:CNKI:SUN:XLXD.0.2014-05-001.

58. Zijlema WL, Triguero-Mas M, Smith G, et al. The relationship between natural outdoor environments and cognitive functioning and its mediators[J]. Environ Res. 2017;155:268-75. doi:10.1016/j.envres.2017.02.017.

59. Theodoropoulou E, Stavrou NAM, Karteroliotis K. Neighborhood environment, physical activity, and quality of life in adults: Intermediary effects of personal and psychosocial factors[J]. JOURNAL OF SPORT AND HEALTH SCIENCE. 2017;6(1):96-102. doi:10.1016/j.jshs.2016.01.021.

60. MacKinnon DP, Lockwood CM, Hoffman JM, et al. A comparison of methods to test mediation and other intervening variable effects.[J]. Psychol Methods, 2002,7(1):83-104. doi:10.1037/1082-989X.7.1.83.

61. Wen ZL, Zhang L, Hou JT, et al. Intermediary Effect Test Procedure and Its Application [J]. Psychological News. 2004;36(5):614-20. doi:CNKI:SUN:XLXB.0.2004-05-016.

62. Fang J, Zhang MJ, Qiu HZ. The Test Method and Effect Measurement of Mediation Effect: Review and Prospect [J]. Psychological development education. 2012;28(01):105-11. doi:10.16187/j.cnki.issn1001-4918.2012.01.015.

63. Hayes AF. Beyond Baron and Kenny: Statistical Mediation Analysis in the New Millennium[J]. Communication monographs. 2009;76(4):408-20. doi:10.1080/03637750903310360.

64. Hayes AF. PROCESS: A Versatile Computational Tool for Observed Variable Mediation, Moderation, and Conditional Process Modelin [White paper].Retrieved from http://www.afhayes.com/public/process2012.pdf.

65. [EB/OL]. http://www.afhayes.com/public/process2012.pdf.

66. Fritz MS, MacKinnon DP. Required Sample Size to Detect the Mediated Effect[J]. Psychol Sci. 2016;18(3):233-9. doi:10.1111/j.1467-9280.2007.01882.x.

67. Mackinnon DP. Introduction to Statistical Mediation Analysis[M]. McGraw-Hill. 2008. Available online: https://psycnet.apa.org/record/2008-04188-000 (accessed on 3 February2021).

68. GOEL N, ETWAROO GR. Bright light, negative air ions and auditory stimuli produce rapid mood changes in a student population: a placebo-controlled study[J]. Psychol Med. 2006;36(9):1253-63. doi:10.1017/S0033291706008002.

69. Watanabe I, Noro H, Ohtsuka Y, et al. Physical effects of negative air ions in a wet sauna[J]. Int J Biometeorol. 1997;40(2):107-12. doi:10.1007/s004840050028.

70. Jiang S, Ma A, Ramachandran S. Negative Air lons and Their Effects on Human Health and Air Quality Improvement[J]. Int J Mol Sci. 2018;19(10):2966. doi:10.3390/ijms19102966.

71. Yan X, Wang H, Hou Z, et al. Spatial analysis of the ecological effects of negative air ions in urban vegetated areas: A case study in Maiji, China[J]. Urban Forestry \& Urban Greening, 2015,14(3):pp. 636-45.

doi:10.1016/j.ufug.2015.06.010.

72. Ministry of Ecology and Environment. Environmental noise emission standards for social life(GB 22337-2008)[S]. China Environmental Science; 2008.

73. Basner M, Babisch W, Davis A, et al. Auditory and non-auditory effects of noise on health[J]. The Lancet. 2014;383(9925):1325-32. doi:10.1016/S0140-6736(13)61613-X.

Page 22/27 
74. Triguero-Mas M, Dadvand $\mathrm{P}$, Cirach $\mathrm{M}$, et al. Natural outdoor environments and mental and physical health: Relationships and mechanisms[J]. Environ Int. 2015;77:35-41. doi:10.1016/j.envint.2015.01.012.

75. Gascon M, Triguero-Mas M, Martinez D, et al. Mental Health Benefits of Long-Term Exposure to Residential Green and Blue Spaces: A Systematic Review[J]. INTERNATIONAL JOURNAL OF ENVIRONMENTAL RESEARCH AND PUBLIC HEALTH, 2015,12(4):pp. 4354-79. doi:10.3390/ijerph120404354.

76. Kondo M, Fluehr J, McKeon T, et al. Urban Green Space and Its Impact on Human Health[J]. International Journal of Environmental Research Public Health. 2018;15(3):445. doi:10.3390/ijerph15030445.

77. Humpel N, Owen N, Leslie E. Environmental factors associated with adults' participation in physical activity - A review[J]. AMERICAN JOURNAL OF PREVENTIVE MEDICINE, 2002,22(PII S0749-3897(01)00426 - 33):188-199. doi: 10.1016/S0749-3797(01)00426-3.

78. Sun BD, Yan H, Zhang TL. The impact of the built environment of the community on health: an empirical study based on the individual overweight of residents [J]. Acta Geogr Sin. 2016;71(10):1721-30. doi:CNKI:SUN:DLXB.0.2016-10006.

79. Zeng XY. Study on the Allocation Model of Near-Natural Plant Communities in Urban Forests in Chengdu [D]. Sichuan Agricultural University, 2009. Available online: https://kns.cnki.n et $/ \mathrm{KCMS} /$ detail $/$ detail.aspx?dbname = CDFD0911\&filename $=$ 2009258837.nh (accessed on 3 February2021).

80. Koohsari MJ, Mavoa S, Villanueva K, et al. Public open space, physical activity, urban design and public health: Concepts, methods and research agenda[J]. Health Place. 2015;33:75-82. doi:10.1016/j.healthplace.2015.02.009.

81. Wang Y, Chau CK, Ng WY, et al. A review on the effects of physical built environment attributes on enhancing walking and cycling activity levels within residential neighborhoods[J]. Cities. 2016;50:1-15. doi:10.1016/j.cities.2015.08.004.

82. Morais MVBD, Freitas EDD, Urbina Guerrero VV, et al. A modeling analysis of urban canopy parameterization representing the vegetation effects in the megacity of São Paulo[J]. Urban Climate. 2016;17:102-15. doi:10.1016/j.uclim.2016.04.004.

83. de Vries S, van Dillen SME, Groenewegen PP, et al. Streetscape greenery and health: Stress, social cohesion and physical activity as mediators[J]. Soc Sci Med. 2013;94:26-33. doi:10.1016/j.socscimed.2013.06.030.

84. Yu Z, Yang G, Zuo S, et al. Critical review on the cooling effect of urban blue-green space: A threshold-size perspective[J]. Urban Forestry Urban Greening. 2020;49:126630. doi:10.1016/j.ufug.2020.126630.

85. Fung CKW, Jim CY. Influence of blue infrastructure on lawn thermal microclimate in a subtropical green space[J]. SUSTAINABLE CITIES AND SOCIETY, 2020,52(101858). doi:10.1016/j.scs.2019.101858.

86. Targino AC, Coraiola GC, Krecl P. Green or blue spaces? Assessment of the effectiveness and costs to mitigate the urban heat island in a Latin American city[J]. Theoret Appl Climatol. 2019;136(3-4):971-84. doi:10.1007/s00704018-2534-1.

87. Sini J, Anquetin S, Mestayer PG. Pollutant dispersion and thermal effects in urban street canyons[J]. Atmos Environ. 1996;30(15):2659-77. doi:https://doi.org/10.1016/1352-2310(95)00 321-5.

88. McCormack GR, Shiell A. In search of causality: a systematic review of the relationship between the built environment and physical activity among adults[J]. Int J Behav Nutr Phys Act. 2011;8(1):125. doi.

89. Wu XJ. Research on the Livability of Public Space in Urban Communities [D]. Central China Normal University, 2010. Available online: https://kns.cnki.net/KCMS/detail/deta il.aspx?dbname = CDFD0911\&filename = 1011038099.nh (accessed on 3 February2021).

90. James P, Hart JE, Banay RF, et al. Exposure to Greenness and Mortality in a Nationwide Prospective Cohort Study of Women[J]. Environ Health Perspect. 2016;124(9):1344-52. doi:10.1289/ehp.1510363. 
91. Selmi W, Weber C, Riviere E, et al. Air pollution removal by trees in public green spaces in Strasbourg city, France[J]. URBAN FORESTRY \& URBAN GREENING, 2016,17:192-201. doi: 10.1016/j.ufug.2016.04.010.

92. Vos PEJ, Maiheu B, Vankerkom J, et al. Improving local air quality in cities: To tree or not to tree?[J]. Environ Pollut. 2013;183:113-22. doi:10.1016/j.envpol.2012.10.021.

93. Janhäll S. Review on urban vegetation and particle air pollution - Deposition and dispersion[J]. Atmos Environ. 2015;105:130-7. doi:10.1016/j.atmosenv.2015.01.052.

94. Chen HM, Zhang YF, Wang JY, et al. Research on Summer Thermal Comfort of Naturally Ventilated Buildings in Hot and Humid Areas in my country: Taking Guangzhou as an Example [J]. Heating Ventilating Air Conditioning. 2010;40(02):96-101. doi:CNKI:SUN:NTKT.0.2010-02-027.

95. BARRADAS VL. Air temperature and humidity and human comfort index of some city parks of Mexico City[J]. Int J Biometeorol. 1991;35(1):24-8. doi:10.1007/BF01040959.

\section{Figures}

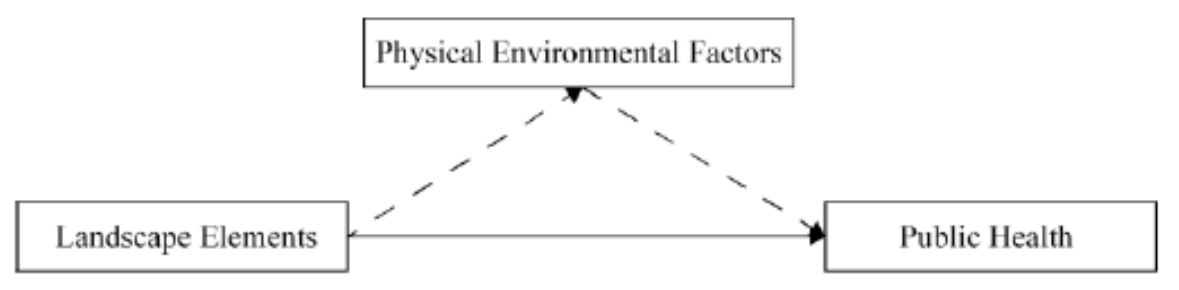

$--\rightarrow$ Indirect Impact $\longrightarrow$ Direct Impact

\section{Figure 1}

Schematic diagram of the study's theoretical framework

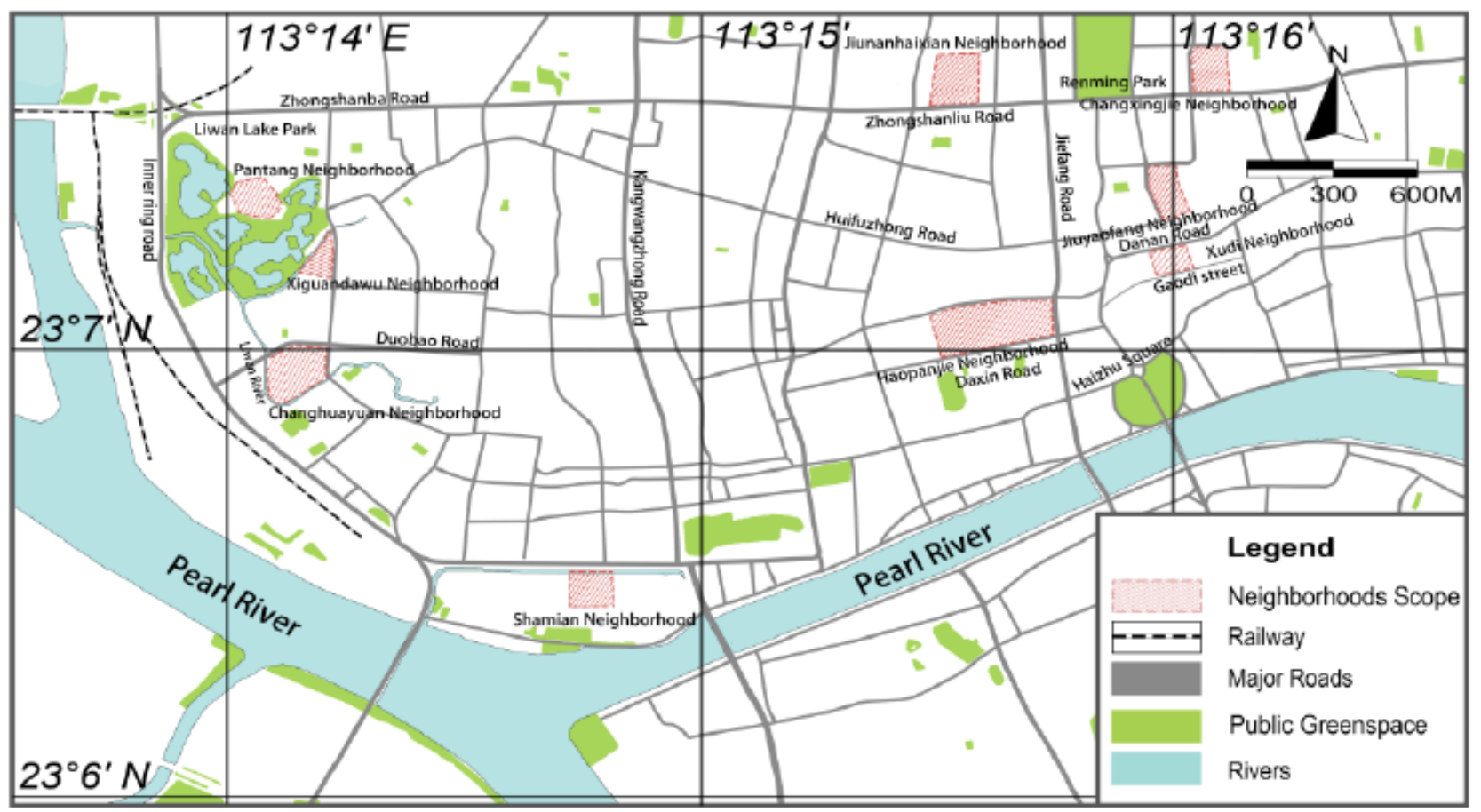




\section{Figure 2}

Map showing locations of the nine sampling sites

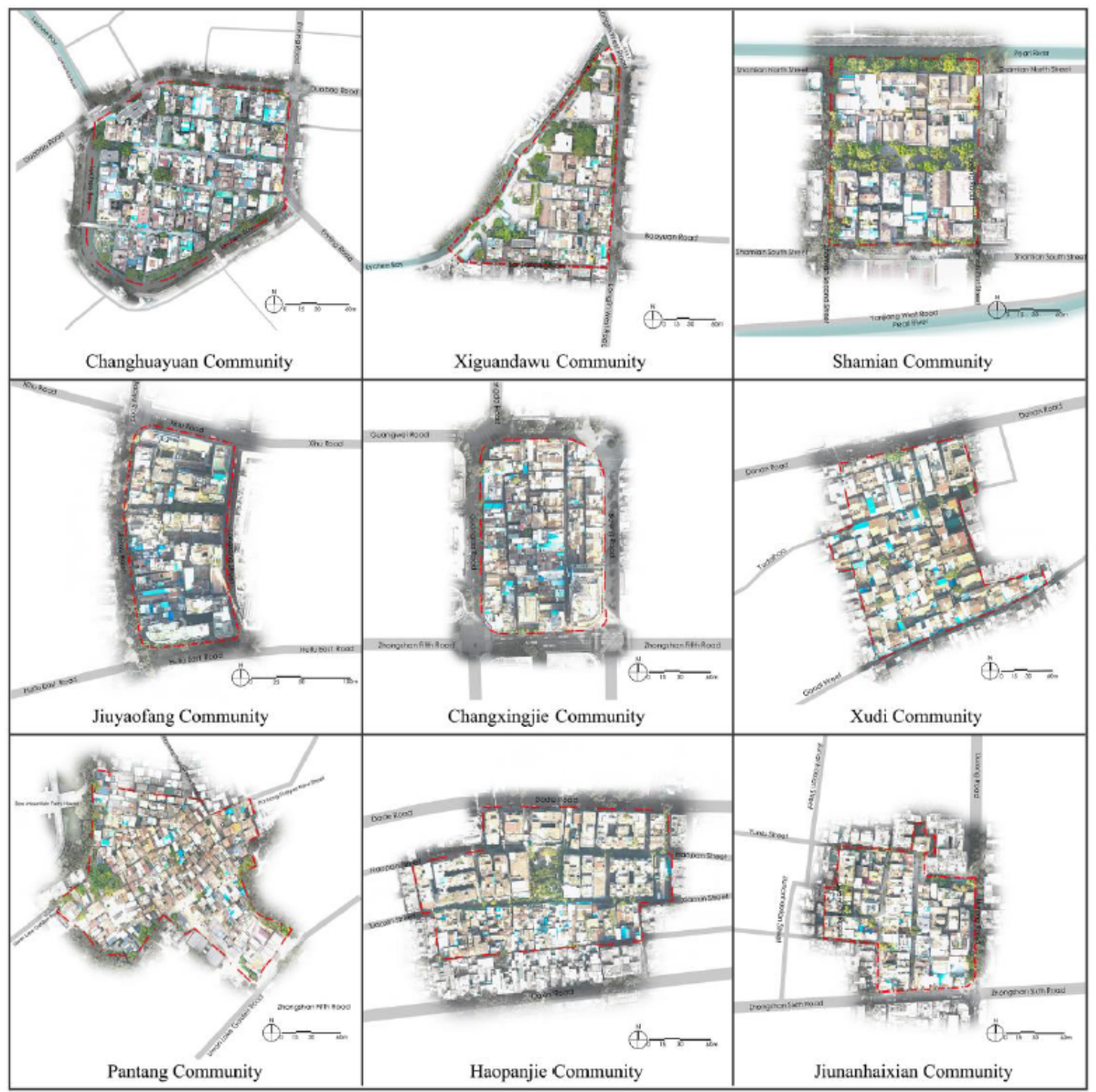

Figure 3

Orthomosaic maps of the sampling sites 


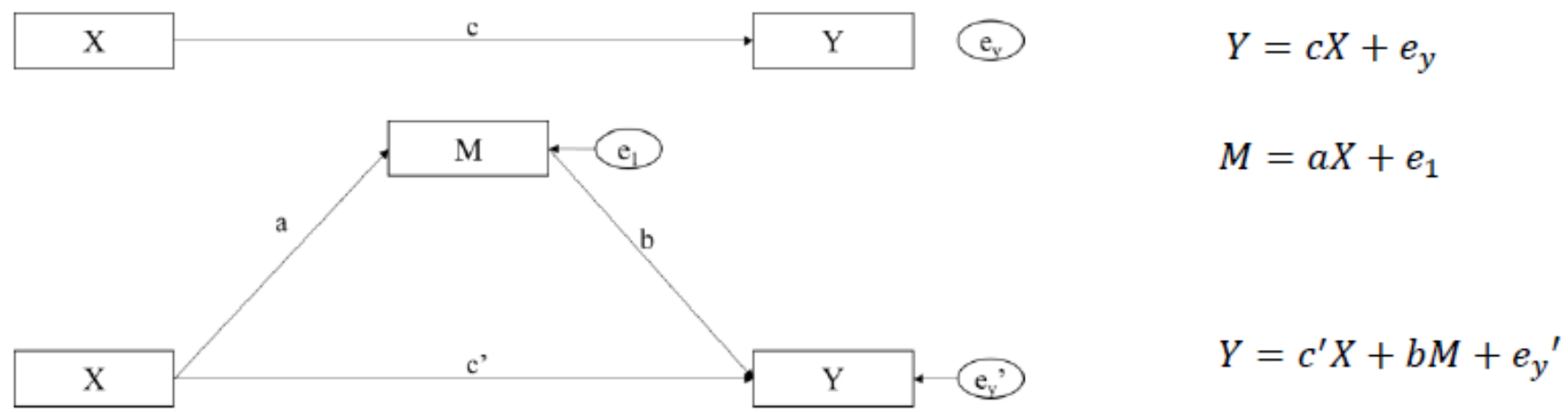

Figure 4

Schematic diagram of a mediation model

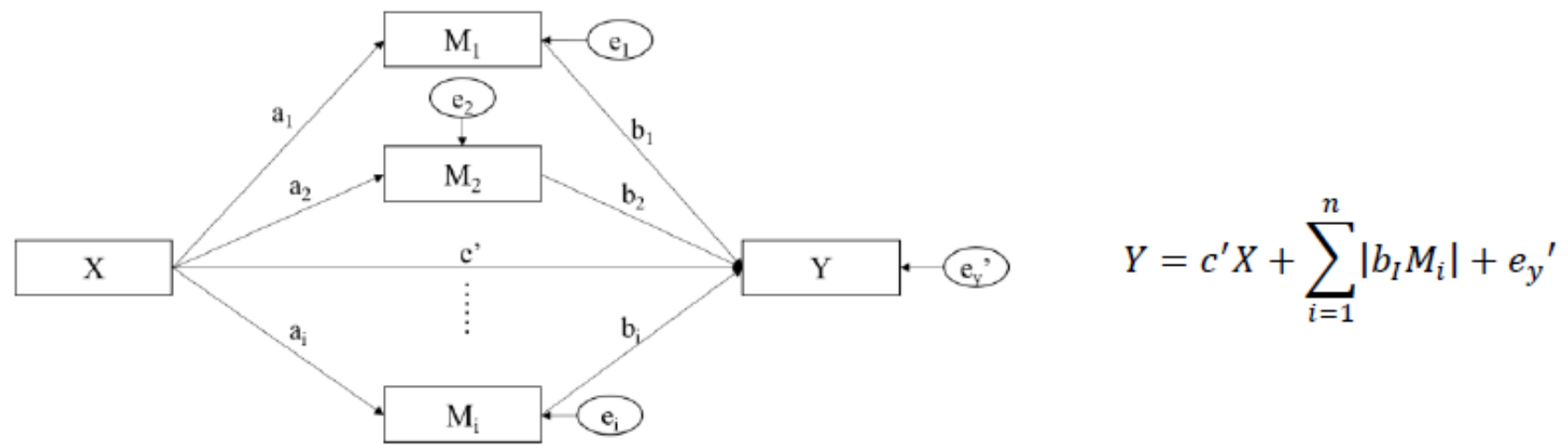

Figure 5

Schematic diagram of a multiple mediation model
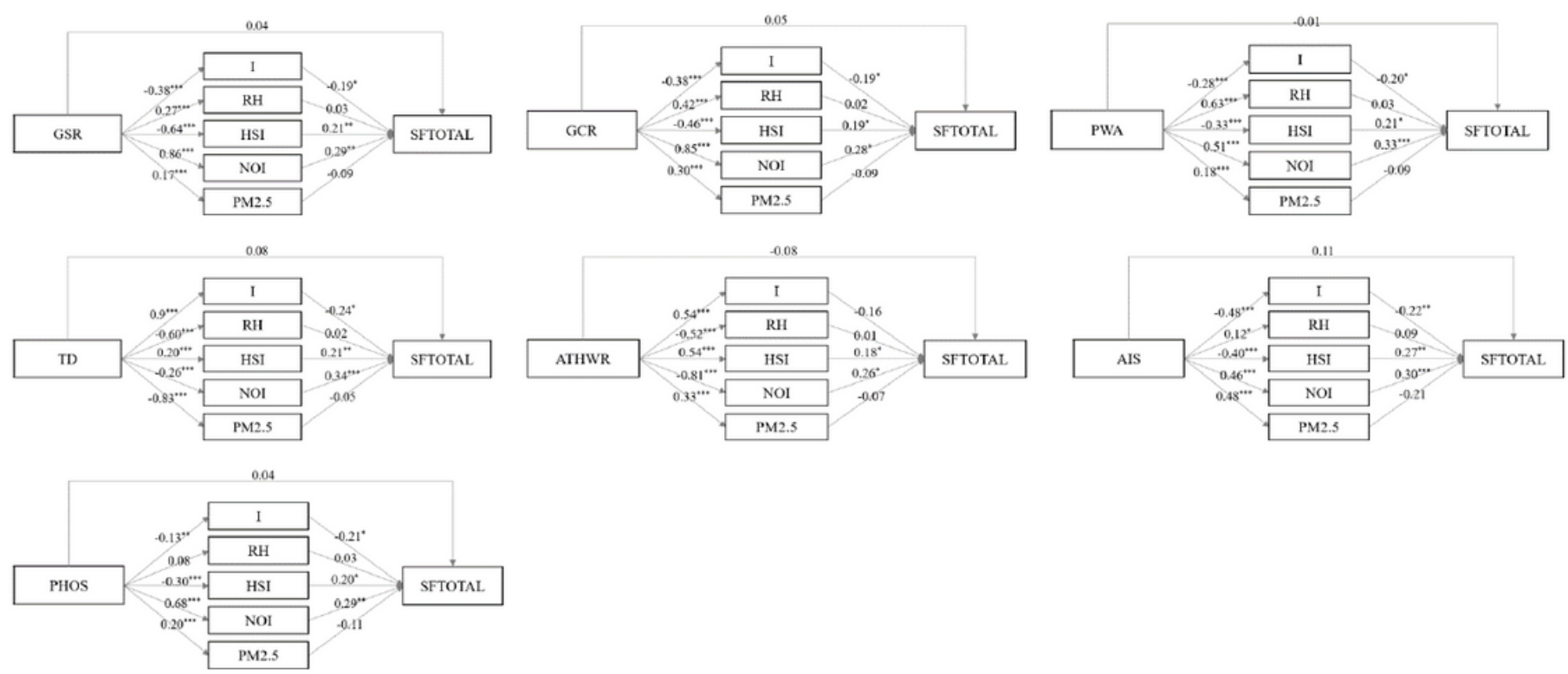


\section{Figure 6}

Pathway diagram of adjusted landscape elements' influences on public health mediated by physical environmental factors Abbreviations: All models are adjusted for age and education as covariates. GSR, green space ratio; GCR, green coverage ratio, TGCR, tree green cover ratio; PWA, percentage of water area; TD, trail density; ATHWR, average trail height to width ratio; AIS, average intersection spacing; PHOS, percentage of hard open space; I, Illumination; $\mathrm{RH}$, Relative Humidity; HSI, Heat Stress Index; NOI- Negative Oxygen lons, PM2.5, Fine Particulate Matter. 